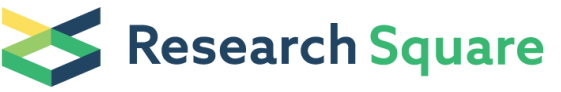 \\ Preprints are preliminary reports that have not undergone peer review. \\ They should not be considered conclusive, used to inform clinical practice, or referenced by the media as validated information.
}

\section{Nitro-oxidized Carboxycellulose Nanofibers From Moringa Plant: Effective Bioadsorbent for Mercury Removal}

\section{HUI CHEN}

Stony Brook University https://orcid.org/0000-0003-3337-0975

\section{Sunil K. Sharma}

Stony Brook University College of Arts and Sciences

\section{Priyanka R. Sharma}

Stony Brook University College of Arts and Sciences

\section{Kai Chi}

Stony Brook University College of Arts and Sciences

\section{Eric Fung}

Stony Brook University College of Arts and Sciences

\section{Katherine Aubrecht}

Stony Brook University College of Arts and Sciences

\section{Ngonye Keroletswe}

Botswana Institute for Technology Research and Innovation

\section{Samuel Chigome}

Botswana Institute for Technology Research and Innovation

Benjamin S Hsiao ( $\boldsymbol{D}$ benjamin.hsiao@stonybrook.edu )

Department of Chemistry Stony Brook University Stony Brook, New York

\section{Research Article}

Keywords: Nitro-oxidization, cellulose nanofibers, mercury removal, moringa, adsorption, mineralization

Posted Date: April 2nd, 2021

DOl: https://doi.org/10.21203/rs.3.rs-368266/v1

License: (c) (1) This work is licensed under a Creative Commons Attribution 4.0 International License. Read Full License

Version of Record: A version of this preprint was published at Cellulose on July 14th, 2021. See the published version at https://doi.org/10.1007/s10570-021-04057-5. 

3

4

5

6

7

8

9

10

11

12

13

14

15

16

17

18

19

20

21

22

23

16

7

8

\section{Nitro-oxidized Carboxycellulose Nanofibers from Moringa Plant: Effective}

\section{Bioadsorbent for Mercury Removal}

\author{
Hui Chen ${ }^{1 \dagger}$, Sunil K. Sharma ${ }^{1 \dagger}$, Priyanka R. Sharma ${ }^{1 *}$, Kai Chi ${ }^{1}$, Eric Fung ${ }^{1}$, \\ Katherine Aubrecht ${ }^{1}$, Ngonye Keroletswe ${ }^{2}$, Samuel Chigome ${ }^{2}$, Benjamin S. Hsiao ${ }^{1 *}$ \\ ${ }^{1}$ Department of Chemistry \\ Stony Brook University
}

Stony Brook, New York 11794-3400, United States

${ }^{2}$ Botswana Institute for Technology Research and Innovation

Private Bag 0082

Gaborone, Botswana

$\dagger$ Authors HC and SKS have equal contribution.

* Corresponding authors.

PRS: Tel: +16315423506, E-mail: priyanka.r.sharma@stonybrook.edu;

22 BSH: Tel: +16316327793, E-mail: benjamin.hsiao@stonybrook.edu 


\section{Abstract}

Mercury contamination in drinking water is a worldwide problem due to its severely harming

27 effects on the human body. A nanostructured natural bioadsorbent, carboxycellulose nanofiber extracted from raw moringa plant using the nitro-oxidation method (termed NOCNF), capable of

29 effectively remediating this problem has been demonstrated. Nitro-oxidation is a simple approach that can extract carboxylated nanocellulose directly from raw biomass. In this study, the produced NOCNF contained a large density of carboxylate groups on the cellulose surface $(0.97 \mathrm{mmol} / \mathrm{g})$,

32 capable of removing $\mathrm{Hg}^{2+}$ ions by simultaneous electrostatic-interactions and mineralization processes. Using the Langmuir analysis, the adsorption results indicated that the highest $\mathrm{Hg}^{2+}$

34 removal capacity of this NOCNF was $257.07 \mathrm{mg} / \mathrm{g}$, which is higher than most of the reported 35 values. The interactions between $\mathrm{Hg}^{2+}$ and NOCNF were further characterized by Fourier36 transform infrared spectroscopy (FTIR), scanning electron microscopy/energy dispersive 37 spectroscopy (SEM/EDS), transmission electron microscopy (TEM) with electron diffraction and wide-angle X-ray diffraction (WAXD) methods, suggesting the existence of two distinct removal 39 mechanisms: predominant adsorption at low $\mathrm{Hg}^{2+}$ concentrations $(<250 \mathrm{ppm})$ and predominant 40 mineralization at high $\mathrm{Hg}^{2+}$ concentrations (> $1000 \mathrm{ppm}$ ). The applications of NOCNF were 41 illustrated in both suspension form, as an adsorbent/coagulant, and dry powder form using 42 filtration column. The results indicated that NOCNF in suspension exhibited a higher maximum 43 removal efficiency of $81.6 \%$ as compared to the dry state of $74.3 \%$. This work demonstrated the 44 feasibility of extracting nanostructured adsorbents from biomass feedstocks to tackle the $\mathrm{Hg}^{2+}$ 45 contamination problem in drinking water. 


\section{$47 \quad$ Keywords}

49 Nitro-oxidization, cellulose nanofibers, mercury removal, moringa, adsorption. mineralization

50

51 Declarations

52

53 Funding is from National Science Foundation (DMR-1808690); Authors have no conflicts of

54 interest; Data and material are all transparent.

55

56 Introduction

57

58 Mercury is a well-recognized harmful pollutant due to its carcinogenicity, mutagenicity and 59 teratogenicity.(Zhang, Nriagu et al. 2005) For example, high concentration of mercury in the 60 human body can cause tyrosinemia, a disease associated with impairment of pulmonary and kidney

61 function, chest pain and dyspnea. One main source of the mercury intake is through the 62 consumption of contaminated fish. In 1956, a horrifying 'Minamata disaster' occurred in Japan, 63 where people had unknowingly consumed shellfishes contaminated with mercury.(Harada 1995, 64 Rio and Delebarre 2003) Although it has been more than 50 years since the incident, many victims 65 still suffer irreversible damage in their central nervous system. This is because mercury ions can 66 bind to varying proteins in the nervous and renal systems, leading to permanent injury. (Lai, Wong 67 et al. 1993)

68

69 Due to the acute health threats to humans, the EPA permitted discharge limit of the total mercury 70 amount in wastewater is $10 \mathrm{mg} / \mathrm{L}$, where the limit for drinking water is $2 \mathrm{mg} / \mathrm{L} .(\mathrm{Nam}$, Gomez- 
71 Salazar et al. 2003)-(Zabihi, Ahmadpour et al. 2009) Meanwhile, the Word Health Organization

72 (WHO) recommends a maximum uptake of $0.3 \mathrm{mg}$ per week at $1 \mathrm{mg} / \mathrm{L}$ as the maximum acceptable

73 concentration in drinking water.(Zhang, Nriagu et al. 2005) Mercury pollution in the aquatic

74 environment is commonly generated from chloralkali plants, paper and pulp industries, oil

75 refining, electrical, rubber processing and fertilizer industries.(Baeyens, Ebinghaus et al. 1997,

76 Chiarle, Ratto et al. 2000) A plenty of physical and chemical strategies have been investigated and

77 applied for mercury remediation in contaminated drinking water, such as solvent extraction, ion-

78 exchange, precipitation, membrane separation, reverse osmosis, coagulation and

79 photoreduction.(International Symposium on Metals Speciation, Recovery et al. , Larson and

80 Wiencek 1992, Skubal and Meshkov 2002) These methods often require either high consumption

81 of energy or usage of large quantitiy of chemicals. Among these methods, adsorption/coagulation

82 is perhaps one of the more cost-effective techniques for mercury removal. For example, activated

83 aluminum or activated carbons have been used as effective adsorbents for mercury removal in

84 drinking water purification, however, it is still relatively expensive for large-scale operation. (Di

85 Natale, Erto et al. 2011)

86

87 To tackle this problem, we argue that lignocellulosic biomass is an abundant and sustainable

88 resource to develop cost-effective bioadsorbent. (Kim, Shim et al. 2015) In the past two decades,

89 much attention has been given to develop nanocellulose in a broad range of water purification

90 treatments because of its large surface areas and ample functional groups. (Wang 2019) For

91 example, several studies have been reported that cellulosic nanomaterials containing thiol,

92 carboxyl, sulfonate, and phosphonate groups can all exhibit ability to adsorb positively charged

93 contaminants, such as metal ions, dyes, and chemicals for water purification. (Wang, Guan et al. 
94 2013, Suman, Kardam et al. 2015, Zhu, Dobryden et al. 2015, Liu, Oksman et al. 2016, Sehaqui,

95 Mautner et al. 2016, Thakur and Voicu 2016, Chen, Sharma et al. 2019, Sharma, Sharma et al. 96 2020)

97

98 Recently, a new method to extract carboxylated cellulose nanofiber from raw biomass using nitric 99 acid $\left(\mathrm{HNO}_{3}\right)$ and sodium nitrite $\left(\mathrm{NaNO}_{2}\right)$ mixtures has been demonstrated by our team (we termed 100 this nitro-oxidation process or NOP).(Sharma, Joshi et al. 2017, Sharma, Zheng et al. 2018) The 101 method combines the steps of pulping (delignification) and cellulose oxidation. The proposed 102 mechanisms of NOP are as follows. Nitric acid can facilitate the defibrillation process of raw 103 biomass by degrading non-cellulosic components, such as lignin and hemicellulose, while the 104 generation of $\mathrm{NO}^{+}$ions (by reaction between $\mathrm{HNO}_{3}$ and $\mathrm{NaNO}_{2}$ ) can selectively oxidize the 105 primary hydroxyl groups of the cellulose to introduce negatively charged surface to induce 106 defibrillation. Compared with conventional methods, such as TEMPO-mediated oxidation and 107 carboxymethylation processes, the NOP does not require any pretreatments such as alkali and 108 bleaching to obtain cellulosic materials first, thus largely reducing the consumption of energy, 109 water and chemicals. In addition, the effluent from this process can be neutralized into nitrogen 110 salts as plant fertilizers. (Sharma, Joshi et al. 2017) In our application studies, nitro-oxidized 111 cellulose nanofibers (NOCNF) have been found as an effective adsorbent/coagulant to remove 112 toxic metal ions such as cadmium(Sharma, Chattopadhyay et al. 2018), lead(Sharma, 113 Chattopadhyay et al. 2018), and uranium(Sharma, Chattopadhyay et al. 2017, Sharma, Sharma et 114 al. 2020) from water. 
116 In this study, we report that NOCNF, extracted directly from raw moringa plants by NOP, can also

117 be an effective bioadsorbent for water remediation such as mercury removal. Moringa plant is is a

118 native species in parts of Africa and Asia, and its products have well-known antifungal, antiviral,

119 antidepressant, and anti-inflammatory properties. In specific, seeds from Moringa tree have been

120 shown to have unique water purification properties.(Kalibbala, Wahlberg et al. 2009) Here we

121 investigate if the moringa plant itself can be a suitable feedstock for preparing the adsorbents. This

122 is because the hemicellulose content of moringa plant is relatively high ( 45\%) (Melesse and

123 Berihun 2013), which can facilitate the defibrillation process in NOP to produce cellulose

124 nanofibers. For the mercury remediation study, we demonstrate the effectiveness of moringa-

125 derived NOP as adsorbents in two different forms: suspension form as typical absorbent/coagulant,

126 and dry form as adsorbent substrate in filtration column. The study also examines the adsorption

127 mechanisms of the mercury removal by the oppositely charged NOCNF. We demonstrate that at

128 low $\mathrm{Hg}^{2+}$ concentrations $(<250 \mathrm{ppm})$, the removal process is mainly dominated by the electrostatic

129 interactions between $\mathrm{Hg}^{2+}$ and $\mathrm{COO}^{-}$on the NOCNF surface, where at high $\mathrm{Hg}^{2+}$ concentrations (>

$1301000 \mathrm{ppm})$, the removal process is dominated by the mineralization of $\mathrm{HgO}$ nanocrystals in the

131 coagulated NOCNF scaffold.

132

133 Experimental Part

134

135 Materials

136

137 Crushed moringa straw samples, without any pretreatments, from Botswana was used as the

138 biomass feedstock. Nitric acid (ACS reagent, $60 \%$ ), sodium nitrite (ACS reagent $\geq 97 \%$ ), mercury 
139

140

141

142 143

144

145

146

147

148

149

150

151

152

153

154

155

156

157

158

159

160

161

acetate, sodium hydroxide, hydrochloric acid (36\% assay) chemicals were purchased from the Fisher Scientific. All chemicals were used without any further purification.

\section{Extraction of NOCNF from Moringa Plant}

NOCNF extracted from moringa feedstock were carried out using NOP with procedures similar to those reported earlier. (Sharma, Joshi et al. 2017) In brief, $2 \mathrm{~g}$ of raw moringa sample was placed in a three-neck round bottom flask, where $28 \mathrm{~mL}$ nitric acid (60 wt.\%, 0.365 mol) was added slowly to completely wet and immerse the biomass. Subsequently, $6.957 \mathrm{mmol}$ of sodium nitrite (0.96 g) was added to the mixture under continuous stirring. Upon addition of sodium nitrite, red gases $\left(\mathrm{NO}_{\mathrm{X}}\right)$ were formed. The mouths of flask were covered with glass stoppers immediately to stop gases from leaking. The reaction was performed at $40{ }^{\circ} \mathrm{C}$ for $16 \mathrm{~h}$ followed by quenching using $250 \mathrm{~mL}$ of distilled water to stop the reaction. The product was settled down under gravity and the supernatant was decanted off to remove the mixture of excessive acid, degraded lignin and oligosaccharides. The above step of decantation process was repeated for 2-3 times until the fibers started to suspend in water. After that, the fibers were centrifuged at $3000 \mathrm{rpm}$ for $10 \mathrm{~min}$, till the $\mathrm{pH}$ of supernatant reached above 2.5 . Then, the fibers were transferred to a dialysis bag (6-8 $\mathrm{kDa})$ for dialysis until the conductivity of water reached below $5 \mu \mathrm{S}$. The extracted fibers contained carboxyl groups $(\mathrm{COOH})$, which were subsequently converted to carboxylate groups $\left(\mathrm{COO}^{-}\right)$by treatment with $8 \%$ of sodium bicarbonate. The fibers were again introduced to dialysis until the conductivity of dialysis water reached below $5 \mu \mathrm{S}$. Finally, the fibers were fibrillated to nanocellulose by passing the $0.2 \mathrm{wt} \%$ fiber suspension through a high pressure homogenizer at 250 bar for 1 cycle. The yield of NOCNF obtained was $50 \mathrm{wt} \%$. 
Sample Characterization

165 The raw moringa samples and extracted NOCNF were characterized using Fourier transform 166 infrared spectroscopy (FTIR, PerkinElmer Spectrum One instrument-ATR mode), conductometric 167 titration, thermogravimetric analysis (TGA, PerkinElmer STA-6000), transmission electron 168 microscopy (TEM, FEI Tecnai G2 Spirit BioTWIN instrument), atomic force microscopy (AFM, 169 Bruker Dimesion ICON scanning probe microscope), scanning electron microscopy (SEM, Zeiss 170 LEO 1550 SFEG-SEM) with energy dispersive X-ray spectroscopy (EDS) capability, and wide 171 angle X-ray diffraction (WAXD, Benchtop Rigaku MiniFlex 600). The detailed descriptions of 172 these techniques are outlined in the Supporting Information (SI).

173

174 The major chemical compositional analysis (i.e., cellulose, hemicellulose, lignin, ash, and 175 extractives) of raw moringa sample and NOCNF was performed by the Celignis Company in 176 Ireland. The analysis was in accordance with the US standard, i.e., NREL standard laboratory 177 analytical procedure TP-510-42623.(Sluiter, Hames et al. 2010) In brief, the following analytical 178 procedures were carried out: (1) acid hydrolysis of samples, (2) determination of acid soluble 179 lignin (ASL) using UV-Vis spectroscopy, (3) gravimetric determination of klason lignin (KL), and 180 (4) chromatographic analysis of hydrolysate. 
In this study, $\mathrm{Hg}^{2+}$ solutions with concentrations ranging from 2.5 to $1000 \mathrm{ppm}$ were first prepared,

187 where these solutions were subsequently mixed with a NOCNF suspension as an 188 adsorbent/coagulant. In specific, $2 \mathrm{~mL}$ of heavy metal stock solution (2.5 to $1000 \mathrm{ppm})$ was slowly 189 added with $2 \mathrm{~mL}$ of NOCNF suspension $(0.40 \mathrm{wt} \%)$ in a test tube. Upon mixing, the floc, 190 containing both aggregated $\mathrm{Hg}$ and NOCNF components, was formed and settled down to the 191 bottom of the tube. The non-flocculated supernatant was then passed through a $0.22 \mu$ filter to 192 remove any fiber residues, but not $\mathrm{Hg}^{2+}$ ions. The obtained solution was diluted before submitting 193 for ICP-MS measurements.

195 Additionally, the effect of $\mathrm{pH}$ on the adsorption of $\mathrm{Hg}^{2+}$ by NOCNF was investigated. In this 196 evaluation, $100 \mathrm{ppm} \mathrm{Hg}^{2+}$ solutions at different $\mathrm{pH}$ values: 3, 5, 7, 9 and 11, were prepared. 197 Subsequently, $2 \mathrm{~mL}$ of NOCNF suspension was added to $2 \mathrm{~mL}$ of varying $\mathrm{Hg}^{2+}$ solutions. Similar 198 to the above procedure, the non-floc portion were extracted, diluted 1000 times and filtered 199 through a $0.22 \mu$ filter for ICP-MS analysis. The ICP-MS results were used to calculate the mercury 200 removal efficiency of NOCNF.

201

202 The $\mathrm{Hg}^{2+}$ adsorption evaluation of NOCNF was performed by using the data obtained from the 203 ICP-MS analysis. In specific, the adsorption capacity at equilibrium $(Q e)$ and equilibrium 204 concentration of adsorbate $(\mathrm{Ce})$ were calculated, where their relationship was evaluated by using 205 both Langmuir and Freundlich isotherm models. The Langmuir model is based on the assumption 206 of monolayer adsorption on the active site of the adsorbent, whereas the Freundlich model is based 
207 on the assumption of multilayer adsorption on the active site of the adsorbent. The Langmuir model

208 can be expressed as follows.

$$
\frac{C e}{Q e}=\frac{C e}{Q m}+\frac{1}{Q m b} \quad \text { Eq. } 1
$$

210 where $Q m$ (the maximum adsorption capability) and $b$ (the Langmuir constant) can be calculated

211 from the intercept and the slope of the CelQe versus $C e$ plot. (Wang and Kuo 2007) In contrast, the 212 Freundlich model can be expressed as follows.

$$
\lg Q e=\frac{1}{n} \lg C e+\lg K_{f} \quad \text { Eq. } 2
$$

214 where $K_{f}$ and $n$ are characteristic constants of the system. (Cui, Liu et al. 2016)

216 Characterization of Hg-NOCNF Floc

218 The floc samples formed from the mixing of $\mathrm{Hg}^{2+}$ solutions and NOCNF suspension were 219 characterized by different techniques including FTIR, TEM with electron diffraction, SEM/EDS 220 and WAXD to determine the mechanisms of the mercury removal by NOCNF. In addition, the 221 hydrophobicity of the floc sample was analyzed by an optical contact angle meter (CAM200, KSV 222 instruments, LID), which is described in the Supporting Information (SI).

224 Preparation of Filtration Column for Dry NOCNF Adsorbent

226 The filtration column using freeze dried NOCNF samples was also carried out to test the $\mathrm{Hg}^{2+}$ 227 removal efficiency. In specific, $3 \mathrm{~g}$ of dried NOCNF samples was used to fill a filtration column

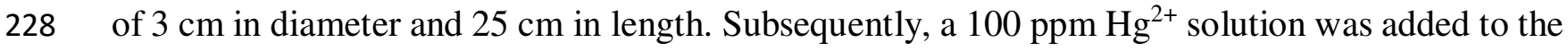


229 top of the column to initiate the test. A total number of 10 additions with an increment of $15 \mathrm{~mL}$ 230 of $\mathrm{Hg}^{2+}$ solution for each addition was poured into the column, and the output filtrate obtained 231 from bottom was collected and labeled accordingly. The filtrate was diluted 1000 times and then 232 submitted for ICP-MS measurements. The removal efficiency from the solid NOCNF form in the 233 filtration column was compared with that from the dispersed NOCNF form in suspension.

\section{Results and Disscussion}

\section{Chemical Composition Analysis}

Similar to other cellulose nanofibrils (such as TEMPO-CNF), the $0.4 \mathrm{wt} \%$ NOCNF suspension was translucent and showed viscous and gel-like behavior (as seen in the inset image in Figure 1). This indicates that the nitro-oxidation process is an efficient pathway to defibrillate raw moringa plant even without pretreatments (or delignification step). The chemical compositions of the raw moringa plant and resulting NOCNF were quantitively characterized, and the results are shown in

244 Figure 1. It was seen that the holocellulose (cellulose and hemicellulose), lignin (acid soluble 245 lignin (ASL) and klason lignin (KL)), ash and extractives contents of raw moringa were 54.77\%, $24624.78 \%, 6.48 \%$, and 9.84\%, respectively, while NOCNF exhibited a higher content of 247 holocellulose $(60.3 \%$ - mostly cellulose $)$ and much lower content of lignin (4.0\%). The significant 248 decrease in the non-cellulosic components after NOP confirmed its successful pulping function. 249 We hypothesize that the residual lignin content in NOCNF might be due to the presence of lignin- 
250 carbohydrate complexes, within which stable chemical bonds could resist the cleavage of $\beta-\mathrm{O}-4$

251 ether bods in polyphenolic units.

253 Figure 2 illustrates the likely mechanism of selective cellulose oxidation by the nitro-oxidation 254 process, which is a revised version from the one we proposed earlier. ${ }^{21}$ In this mechanism, the 255 reaction between $\mathrm{HNO}_{3}$ and $\mathrm{NaNO}_{2}$ generates $\mathrm{HNO}_{2}$ and nitroxonium ions $\left(\mathrm{NO}^{+}\right)$, which can 256 selectively attack primary hydroxyl group $\left(-\mathrm{CH}_{2} \mathrm{OH}\right)$ of the cellulose unit at the $\mathrm{C}_{6}$ position and 257 produce $-\mathrm{CH}(\mathrm{OH})_{2}$ group as the intermediate in the first oxidation circle. Subsequently, $-\mathrm{CH}(\mathrm{OH})_{2}$ 258 group can be continuously oxidized into carboxylic groups $(-\mathrm{COOH})$ in the second oxidation 259 circle. Overall, $\mathrm{NO}^{+}$as the oxidizing agent is gained and consumed during the reaction, where the 260 end $\mathrm{N}$-product is the mixture of $\mathrm{NO}_{\mathrm{X}}$ gases. Although the exact compositions of $\mathrm{NO}_{\mathrm{X}}$ gases have 261 not yet been determined, we believe the byproducts will contain three different gases: $\mathrm{NO} \mathrm{NO}_{2}$ 262 and $\mathrm{N}_{2} \mathrm{O}$. $\mathrm{NO}$ nd $\mathrm{NO}_{2}$ can be generated by he following reactions:

$$
\mathrm{R}-\mathrm{CH}_{2} \mathrm{OH}+\mathrm{HNO}_{3} \longrightarrow \mathrm{R}-\mathrm{COOH}+\mathrm{NO}+\mathrm{H}_{2} \mathrm{O}
$$

$$
\mathrm{NO}+2 \mathrm{HNO}_{3} \longrightarrow 3 \mathrm{NO}_{2}+\mathrm{H}_{2} \mathrm{O}
$$

In addition, $\mathrm{N}_{2} \mathrm{O}$ can be produced when $\mathrm{HNO}$ dissociates in water, as reported by Strojny.(Strojny,

266 Iwamasa et al. 1971) In Figure 2, we only indicate $\mathrm{N}_{2} \mathrm{O}$ as a possible end $\mathrm{N}$-product. Other gaseous 267 products will also be possible, which will be experimentally verified in our future study. 
271 Figure 3(i) illustrates the FTIR spectra of raw moringa plant, extracted NOCNF and Hg-NOCNF

272 floc after the remediation study. The FTIR spectrum of the moringa plant showed several

273 distinctive peaks: $3328 \mathrm{~cm}^{-1}$ corresponding to the $-\mathrm{OH}$ stretching and $2900 \mathrm{~cm}^{-1}$ corresponding to

274 the $\mathrm{C}-\mathrm{H}$ symmetrical stretching in the cellulose unit; $1515 \mathrm{~cm}^{-1}$ due to the $\mathrm{C}=\mathrm{C}$ symmetrical

275 stretching in the aromatic lignin unit; and 1739, 1602, 1460, 1240, and $810 \mathrm{~cm}^{-1}$ in the xylan unit.

276 In the FTIR spectrum of NOCNF, it was seen that both $\mathrm{OH}$ stretching peak at $3328 \mathrm{~cm}^{-1}$ and C-H

277 stretching peak at $2900 \mathrm{~cm}^{-1}$ became much sharper than those in moringa plant, confirming the

278 hypothesis that some removal of lignin and hemicellulose components took place resulting in the

279 dominant presence of cellulose scaffold. The delignification function of NOP was further verified

280 by the near absence of the $1515 \mathrm{~cm}^{-1}$ peak form the lignin unit. However, the hemicellulose peaks

281 at $1739,1602,1460,1240$, and $810 \mathrm{~cm}^{-1}$ remained visible, suggesting that the removal of

282 hemicellulose in NOCNF is only partial. This is reasonable as the hemicellulose component acts

283 as a crosslinker between cellulose elementary microfibrils, which may not be accessible by the

284 oxidation process.(Chi and Catchmark 2017) It is interesting to note that, the peak at $1602 \mathrm{~cm}^{-1}$

285 due to the stretching motion in the carboxyl group was found to be notably increased in the

286 NOCNF spectrum, verifying the modification of hydroxy group to carboxyl group in the 287 anhydroglucose unit (probably at the C6 position) by NOP.

289 The WAXD pattern of the moringa plant in Figure 3(ii) showed a cellulose I structure with $2 \theta$ 290 angles at 14.8, 16.7, 22.7 and $34.7^{\circ}$, corresponding to (110), (110), (200) and (004) reflection 291 planes, respectively. The peaks at 14.8 and $16.7^{\circ}$ were overlapped, which needed to be 292 deconvoluted to reveal individual intensity and position. This is a quite common in higher plants 293 with cellulose $I_{\beta}$ allomorph structure. For NOCNF, similar WAXD pattern was observed, 
294 suggesting the cellulose crystalline structure was maintained during nitro-oxidation, which only

295 performed the defibrillation process. However, the peak positions of (11̄0) and (110) were found

296 to shift to lower $2 \theta$ values (thus larger d-spacings), reflecting to the slight loosening of the

297 crystalline structure due to cellulose oxidation. The crystallinity index (CI) values for the moringa

298 plant and NOCNF were calculated by the peak height method (Equation S1, Supporting

299 Information), and they were 61.2 and $67.3 \%$, respectively. The slight increase in the crystallinity

300 of NOCNF was mainly due to the reduction of amorphous, non- cellulosic components (lignin)

301 during the nitro-oxidation process.

302

303 The thermogravimetric (TGA) and derivative thermogravimetric (DTG) profiles of raw moringa

304 plant and NOCNF are shown in Figures 3(iii) and 3(iv), respectively. The moringa plant showed

305 the onset of thermal degradation $\left(\mathrm{T}_{\text {onset }}\right.$ ) at $174{ }^{\circ} \mathrm{C}$ with 9 wt $\%$ weight loss and the offset 306 temperature $\left(\mathrm{T}_{\text {offset }}\right)$ was about $764{ }^{\circ} \mathrm{C}$. In contrast, NOCNF exhibited $\mathrm{T}_{\text {onset }}$ at $136{ }^{\circ} \mathrm{C}$ with 15 wt $\%$

307 weight loss and $\mathrm{T}_{\text {offset }}$ at $802{ }^{\circ} \mathrm{C}$. The lower $\mathrm{T}_{\text {onset }}$ value in NOCNF confirmed the removal of more 308 thermally stable lignin component by nitro-oxidization, resulting in the exposure of holocellulose 309 part that is more vulnerable to thermal decomposition. In addition, the earlier initialization of 310 thermal degradation of NOCNF was probably due to the presence of anhydroglucuronic acid 311 units,(Sharma and Varma 2014, Sharma and Varma 2014) consisting of thermally unstable 312 carboxyl groups.

314 The DTG curve of the moringa plant showed a primary peak at $302{ }^{\circ} \mathrm{C}$, corresponding to the 315 degradation of holocellulose moiety(Zhang, Zhao et al. 2013, Ornaghi Júnior, Zattera et al. 2014), 316 and a secondary peak between $402-500{ }^{\circ} \mathrm{C}$, related to the lignin moiety. In contrast, NOCNF 
317 displayed two primary peaks $\left(260{ }^{\circ} \mathrm{C}\right.$ and $\left.300{ }^{\circ} \mathrm{C}\right)$, which are characteristics of oxidized 318 nanocellulose, such as TEMPO-oxidized cellulose. The first peak is due to the decomposition of 319 the anhydroglucuronic acid units, where the surface carboxylate groups can initiate the 320 decarbonation and decarboxylation reactions when subjected to heating. The second peak 321 corresponds to the decomposition of residual un-modified cellulose moiety. In addition, a minor 322 peak in the temperature range of $400-430{ }^{\circ} \mathrm{C}$ was observed in NOCNF, suggesting the lignin 323 component was significantly removed during the nitro-oxidation process, which is consistent with 324 chemical composition results in Figure 1. Overall, the difference in thermal stability between 325 moringa and NOCNF can be attributed to their surface chemistry and degree of polymerization 326 (DP). After nitro-oxidation, a high amount of carboxyl groups is generated on the surface of 327 moringa cellulose, which can initiate the decarbonation and decarboxylation processes at low 328 temperatures. In addition, under the influence of nitric acid pulping and cellulose oxidation by 329 NOP, NOCNF's DP can be greatly reduced, resulting in more reducing ends and initiating sites 330 for depolymerization and decomposition.

332 The carboxylate content of resulting NOCNF was determined by the conductimetric titration 333 technique using Equation S2 in Supporting Information. The result indicated that the carboxylate 334 content of NOCNF was $0.97 \mathrm{mmol} / \mathrm{g}$, which is comparable to NOCNF derived from jute biomass 335 as reported in our previous study.(Sharma, Sharma et al. 2020) The surface charge density of the 336 NOCNF sample was also verified by the zeta potential measurement (see description in the 337 Supporting Information), which yielded a negative zeta potential value of $-59 \mathrm{mV}$ confirming the 338 abundant content of $\mathrm{COO}^{-}$groups on the surface of NOCNF. 
342 A representative TEM image of NOCNF extracted from the moringa plant displayed the 343 nanofibrous morphology as shown in Figure 4(i). In this image, 20 individual fibers were identified 344 and used to estimate the fiber length and fiber width, which were $250-300 \mathrm{~nm}$ and $10-12 \mathrm{~nm}$, 345 respectively. The AFM image (Figure 4(ii)) presented similar nanofibrous morphology in NOCNF, 346 where the height measurement indicated that the average fiber thickness was about $2.1 \mathrm{~nm}$. This 347 indicated that the extracted NOCNF possessed a ribbon shape instead of the circular-like fiber 348 form. The representative SEM image of raw moringa sample is shown in Figure 4(iii), indicating 349 that the initial sample possessed a microscopic fiber form with width in the range of $20-100 \mu \mathrm{m}$ 350 and several mini-meters in length. The morphological characterization of raw moringa fiber and 351 NOCNF clearly confirmed the effective extraction of cellulose fibers from raw biomass using the 352 nitro-oxidation process.

\section{Characterization of NOCNF-Hg Floc}

The FTIR spectrum of the NOCNF-Hg floc sample is illustrated in Figure 3(i)c. In this spectrum,

357 a shift of the carboxylate peak in NOCNF from $1600 \mathrm{~cm}^{-1}$ to $1635 \mathrm{~cm}^{-1}$ in the NOCNF-Hg floc

358 was observed, probably due to the crosslinking between $\mathrm{Hg}^{2+}$ ions and carboxylate $\left(\mathrm{COO}^{-}\right)$groups 359 of NOCNF. However, we note that the intensity of $1635 \mathrm{~cm}^{-1}$ can also be attributed to the presence 360 of the acetate group in the mercury acetate solution used in this study. Figure 5 illustrates the 
361 photographs of the floc formation by mixing 100, 500 and $1000 \mathrm{ppm} \mathrm{of} \mathrm{Hg}^{2+}$ solutions with a 362 NOCNF suspension under neutral condition. It was observed that white flocs were immediately 363 formed, precipitated and settled down in the bottom of the tube in a very short period of time (less 364 than $20 \mathrm{~s}$ ). This indicated that the NOCNF in the suspension form is an excellent adsorption and 365 coagulation agent, capable of finding with $\mathrm{Hg}^{2+}$ ions, resulting in efficient removal of mercury 366 contaminant.

Mechanisms of Hg Removal by NOCNF in Suspension

To understand the interactions between $\mathrm{Hg}^{2+}$ ions and NOCNF in suspension, SEM and EDX 371 images of floc samples formed with different $\mathrm{Hg}^{2+}$ concentrations (250 ppm and $\left.1000 \mathrm{ppm}\right)$ are 372 shown in Figure 6. The two SEM images clearly exhibited the change in morphology of the 373 NOCNF-Hg floc with different amounts of $\mathrm{Hg}^{2+}$. In Figure 6(i), at a low concentration of $\mathrm{Hg}^{2+}$ $374(250 \mathrm{ppm})$, the floc surface was relatively uniform, where individual nanofibers could be 375 identified. However, the presence of $\mathrm{Hg}$ was also apparent in the EDS spectrum. As the $\mathrm{Hg}^{2+}$ 376 concentration increased to $1000 \mathrm{ppm}$, the floc surface became more aggregated, but the individual 377 fiber morphology disappeared. In fact, a few large aggregates were seen in otherwise a relatively 378 smooth surface. These aggregates could be attributed to the mineralization of $\mathrm{HgO}$ on the NOCNF 379 surface. The corresponding EDS spectrum confirmed the larger content of $\mathrm{Hg}$ in the NOCNF-Hg 380 floc $(1000 \mathrm{ppm})$ than that in NOCNF-Hg (250 ppm). In addition to the presence of $\mathrm{Hg}$, EDS also 381 showed the element of $\mathrm{Na}$ from the -COONa on NOCNF. 
383 The different morphology of the NOCNF-Hg floc, containing varying amount of $\mathrm{Hg}$ adsorption, indicates that the adsorption mechanisms between the $\mathrm{Hg}^{2+}$ ions and NOCNF are quite different when the $\mathrm{Hg}^{2+}$ concentration changes. Based on the experimental results, we hypothesize that at 386 low $\mathrm{Hg}^{2+}$ concentration $(<250 \mathrm{ppm})$, the $\mathrm{Hg}^{2+}$ ion behaves like an ionic cross-linking agent, 387 capable of electrostatically interacting with two carboxylate groups $\left(\mathrm{COO}^{-}\right)$on the NOCNF 388 surface. The binding of the $\mathrm{Hg}^{2+}$ ions and carboxylate groups would lead to the neutralization of 389 NOCNF, resulting in further aggregation of NOCNF particles due to hydrophobic interactions. In 390 the NOCNF-Hg floc, the adsorbed/anchored $\mathrm{Hg}$ moiety appeared to act as a nucleation site for the growth of mercury(II) oxide $(\mathrm{HgO})$ nanocrystals on the surface of NOCNF. Most probably, the

392 low $\mathrm{pH}$ value of the system can facilitate the growth of $\mathrm{HgO}$ nanocrystals because the acidic $\mathrm{pH}$ 393 condition can hydrolyze mercury acetate and form unstable mercury hydroxide $\left(\mathrm{Hg}(\mathrm{OH})_{2}\right)$, which 394 subsequently loses water and becomes HgO.(Wang and Andrews 2005)

The mineralization of $\mathrm{HgO}$ nanocrystals was confirmed by WAXD measurement of the floc 397 (Figure 4(iii)), which will be explained later. The similar mineralization occurrence of nanocrystals 398 in the CNF scaffold during remediation has also been reported earlier.(Sharma, Chattopadhyay et 399 al. 2017, Sharma, Chattopadhyay et al. 2018, Sharma, Chattopadhyay et al. 2018) To understand 400 the $\mathrm{HgO}$ mineralization mechanism in this study, the $\mathrm{pH}$ values of the different $\mathrm{Hg}$ solution (at 401 varying concentration) before and after remediation using NOCNF were first measured, and the 402 results are summarized in Table $\mathrm{S} 1$. It was seen that the $\mathrm{pH}$ value decreased upon the increase in 403 the $\mathrm{Hg}$ concentration. For example, at the $\mathrm{Hg}$ concentration of $2.5 \mathrm{ppm}$, the $\mathrm{pH}$ value of the solution 404 was 5.02; while at the concentration of $1000 \mathrm{ppm}$, the $\mathrm{pH}$ value was 3.44. The decrease in $\mathrm{pH}$ was 405 due to the increase in acetate ions $\left(\mathrm{CH}_{3} \mathrm{COO}^{-}\right)$in the solution, formed by dissociation of mercury 
acetate. Upon the addition of NOCNF, the same decreasing trend of the $\mathrm{pH}$ value was seen with the increase in $\mathrm{Hg}$ concentration, but the decrease in $\mathrm{pH}$ was stopped at 4.66 when $1000 \mathrm{ppm}$ of $\mathrm{Hg}$ solution was used. Notably, no mineralization and precipitation were observed with increasing $\mathrm{Hg}$ concentration in the absence of NOCNF. The above finding indicates that NOCNF is playing a crucial role by providing the active site for adsorption and mineralization of $\mathrm{Hg}^{2+}$, leading to high removal efficiency against $\mathrm{Hg}^{2+}$ ions.

The hydrophobicity of the floc sample containing $1000 \mathrm{ppm}$ of $\mathrm{Hg}^{2+}$ was analyzed by the contact angle measurement, and the results are shown in Figure 7(i) (the inset image). This NOCNF-Hg floc sample was found to possess a contact angle of $114.5^{\circ}$, indicating that the $\mathrm{Hg}$ adsorption neutralized the charge on NOCNF resulting in a hydrophobic composite (the as extracted NOCNF has a contact angle about $38^{\circ}$ (Sharma, Chattopadhyay et al. 2018)). The WAXD measurement of the NOCNF-Hg floc sample was carried out to examine its crystal nature. The results are displayed in Figure 7(iii), where the WAXD profile of NOCNF is also included for comparison. It was found that after remediation with $1000 \mathrm{ppm}$ of $\mathrm{Hg}^{2+}$, additional diffraction peaks appeared at $2 \theta$ of 30.8 , $32.3,33.4,38.3$ and $50.9^{\circ}$, which could be indexed as the (011), (110), (020), (101) and (121) lattice planes of $\mathrm{HgO}$ crystals (i.e., the orthorhombic phase of $\mathrm{HgO}$ with a space group of $\mathrm{Imm} 2$; JCPDS No. 72-1141).(Mohadesi, Ranjbar et al. 2014) This evidence supports the growth of HgO nanocrystals in the NOCNF scaffold which is also in agreement with the SEM results from the floc sample at $1000 \mathrm{ppm}$ of $\mathrm{Hg}$ concentration (Figure 6(ii)). The TEM image of the floc sample with 1000 ppm of $\mathrm{Hg}$ concentration is shown in Figure 7(i). Compared to the disperse fiber image of NOCNF (Figure 4(i)), the NOCNF-Hg floc exhibited an aggregated form of nanofiber network containing inorganic nanocrystals shown as black dots in TEM. These black dots, uniformly 
429 dispersed in the fiber aggregate, are associated with the mercury oxide $(\mathrm{HgO})$ particles. This was

430 proven by the electron diffraction measurement of the floc sample, where the result is shown in

431 Figure 7(ii). The electron diffraction patterns of the floc sample showed five strong diffraction

432 rings that could also be indexed as the (011), (110), (020), (101), (121) planes, as shown in WAXD

433 (Figure 7(iii)). We note that in the TEM study, no staining agent was used while preparing the 434 sample; this ensured the absence of any other metal ions except merury.

\section{Assessment of $\mathrm{Hg}^{2+}$ Adsorption Mechanism by NOCNF Suspension}

The behavior of $\mathrm{Hg}^{2+}$ adsorption by NOCNF was evaluated in the $\mathrm{Hg}$ concentration range of 2.5 ppm to $1000 \mathrm{ppm}$. The ICP-MS results were used to calculate the $Q e$ value (i.e., the experimental adsorption capacity of NOCNF) and $\mathrm{Ce} / \mathrm{Qe}$ ratio (i.e., the original $\mathrm{Hg}^{2+}$ concentration of NOCNF divided by the experimental adsorption capacity of $\mathrm{Hg}^{2+}$ ions at equilibrium per gram of NOCNF in suspension). It was found that the adsorption efficiency of $\mathrm{Hg}^{2+}$ by NOCNF decreased from $88.5 \%$ to $47.2 \%$ when the $\mathrm{Hg}$ concentration increased from 2.5 to $1000 \mathrm{ppm}$. Meanwhile, the experimental capacity raised from $0.55 \mathrm{mg} / \mathrm{g}$ to $117.9 \mathrm{mg} / \mathrm{g}$. Using Eq.1, the plot of CelQe versus

446 value of Qe was calculated by multiplying the adsorption efficiency of NOCNF by the ideal 447 adsorption capacity of NOCNF. The results of the ideal adsorption capacity and the experimental 448 capacity of NOCNF are summarized in Table S2 in the Supplementary Information. In addition, 449 the Freundlich adsorption model was also employed to predict the isotherm of $\mathrm{Hg}^{2+}$ remediation 450 process. The plot of $\lg (Q e)$ versus $\lg (C e)$ fitted by the Freundlich equation (Eq. 2) is shown in 451 Figure 8(ii). The fitting parameters, such as the slope and R square value, of these two models are 
summarized in Table 1. Both models exhibited very high R square values: 0.9946 for the Langmuir model, and 0.9951 for the Freundlich model. These results suggest that the adsorption mechanism cannot truly be differentiated based on the different model analysis. Nevertheless, from the analysis of the Langmuir model, the $Q m$ value (the maximum adsorption capacity of the adsorbent) could be calculated, i.e., $257.07 \mathrm{mg} / \mathrm{g}$, which is higher than most adsorbents reported.(Anoop Krishnan and Anirudhan 2002, Puanngam and Unob 2008, Tran, Wu et al. 2015, Anbia and Amirmahmoodi 2016, Guo, Wang et al. 2017, Sajjadi, Mohammadzadeh et al. 2018)

\section{Effect of pH and Time on $\mathrm{Hg}^{2+}$ Remediation by NOCNF Suspension}

The $\mathrm{pH}$ effect on $\mathrm{Hg}^{2+}$ remediation was carried out to assess the removal efficiency of NOCNF in suspension, and the results are summarized in Table S3 in Supporting Information and in Figure 8(iii). It was observed that the removal efficiency increased to $88.9 \%$ when the $\mathrm{pH}$ value increased from 3 to 9. The reason that at $\mathrm{pH}=9$, the highest removal efficiency was obtained is because the maximum negative charge density of NOCNF could be induced by the deprotonation of carboxyl group $\left(\mathrm{COO}^{-}\right)$at alkaline conditions. With a further increase in the $\mathrm{pH}$ value to $11, \mathrm{NOCNF}$ showed a decrease in the removal efficiency to $75.6 \%$. This is because the further increase in $\mathrm{pH}$, the condition might start to degrade NOCNF. In contrast, the removal efficiency of NOCNF at $\mathrm{pH}=3$ was only $35.9 \%$, This is because the acidic conditions could protonate the carboxylate groups on the NOCNF surface, resulting in an acid form $(\mathrm{COOH})$ with less binding sites available to interact with the $\mathrm{Hg}^{2+}$ ions. The above study clearly indicates the $\mathrm{pH}$-dependent characteristic of NOCNF for mecury removal, as the NOCNF suspension can be considered as a weak polyelectrolyte due to the carboxylate group on the particle surface. 
476 The effect of time on the $\mathrm{Hg}^{2+}$ remediation by NOCNF suspension was also evaluated, and the

477 results are shown in Figure 8(iv). It was found that there was no significant change in the removal

478 efficiency when the experiments were performed between $3 \mathrm{~h}$ to $24 \mathrm{~h}$. The removal efficiency was 479 stabilized between $81.1-81.6 \%$, indicating that the removal of $\mathrm{Hg}^{2+}$ by NOCNF took place mainly 480 in the initial hours of the remediation study. This study shows that a swift remediation process can 481 be achieved by using NOCNF suspension as a mercury removal agent.

\section{Comparison with Other Adsorbents}

The comparison of the maximum adsorption capacity $(\mathrm{Qm})$ of different adsorbents for mercury removal is listed in Table 2. Compared to nanomaterials, such as thiol and hydroxyl containing montmorillonite(Tran, Wu et al. 2015), nanoporous carbon grafted with surfacants(Anbia and Amirmahmoodi 2016), and chemically-modified MCM-41 and silica gel(Puanngam and Unob 2008), NOCNF extracted from moringa plants showed the highest maximum adsorption capacity value of $257 \mathrm{mg} / \mathrm{g}$ in the $\mathrm{Hg}$ concentration range of 2.5-1000 ppm. In Table 2, some natural

491 biomaterials, such as coconut husk(Guo, Wang et al. 2017) and activated carbon(Sajjadi, 492 Mohammadzadeh et al. 2018) prepared from different sources have also been included. Among 493 them, one activated carbon presented very good maximum adsorption capacity value of $202 \mathrm{mg} / \mathrm{g}$, 494 although in a very narrow $\mathrm{Hg}$ concentration range of 2.5-4.5 ppm. The activated carbon(Anoop 495 Krishnan and Anirudhan 2002) prepared from bagasse pith also exhibited good maximum 496 adsorption capacity of $172 \mathrm{mg} / \mathrm{g}$ in a wider $\mathrm{Hg}$ concentration range of 50-1000 ppm. But these 497 values are still smaller than that of NOCNF. We believe the good performance of NOCNF should 
498 be independent of the biomass source used. The remarkable mercury removal property of NOCNF 499 in suspension is due to its high surface area, large carboxylate concentration and unique scaffolding 500 capability to induce $\mathrm{HgO}$ mineralization.

\section{Filtration Column using Freeze-Dried NOCNF}

NOCNF suspensions were also freeze-dried into dry powder samples as adsorbent materials in

505 filtration column for the evaluation of mercury removal. In this study, $3 \mathrm{~g}$ of dried NOCNF sample was packed into a column of $15 \mathrm{~cm}$ in length. Subsequently, $100 \mathrm{ppm}$ of $\mathrm{Hg}^{2+}$ solution was passed

507 through the column slowly by gravity. The output $\mathrm{Hg}^{2+}$ solution was collected and tested by the ICP-MS technique, where the results are shown in Table 3. It was seen that the removal efficiency

509 achieved by this gravity-driven column in the first pas of the study was $74.3 \%$, but the removal 510 efficiency began to decrease upon further addition of the $\mathrm{Hg}^{2+}$ solution. With the total passing of $511150 \mathrm{~mL}$ filtrate (10 additions of $15 \mathrm{ml} \mathrm{Hg}^{2+}$ solution) through the column, the removal efficiency 512 was found to be $53.3 \%$. The decrease in the removal efficiency of the column was due to the 513 saturation of carboxyl groups on the NOCNF surface through binding with $\mathrm{Hg}^{2+}$ ions. It was seen 514 that the adsorption results from the use of NOCNF suspension indicated the removal efficiency of $51581.6 \%$ at the $\mathrm{Hg}$ concentration of $100 \mathrm{ppm}$ (Table S2 in Supplementary Information), which is 516 higher than the removal efficiency by using solid NOCNF in filtration column. This can be 517 explained as follows. During freeze drying process, the aggregation of nanocellulose can occur 518 due to the increasing interfibrillar interactions (van der Waal forces and hydrogen bonding), 519 leading to reduced surface area and decreasing binding sites for $\mathrm{Hg}^{2+}$ ions in the NOCNF scaffold. 520 In the filtration column application, the primary adsorption mechanism is dominated by the 
521 electrostatic interactions between carboxylate groups and the $\mathrm{Hg}^{2+}$ ions, where the mineralization 522 process probably does not occur. To improve the total removal efficiency of the column, one needs

523 to increase the total carboxylate content of the adsorbent by raising: (1) the degree of CNF 524 oxidation, (2) the total loading of NOCNF, and (3) the surface area of NOCNF. Furthermore, we 525 argue although the removal efficiency of solid NOCNF is not as good as NOCNF in suspension, 526 the transportation cost of the formal may be much more cost-effective than the latter.

528 Conclusions

530 This work demonstrates an effective nanocellulose-based adsorbent system (in suspension or solid 531 form) for mercury removal that was developed from untreated moringa plant using the nitro532 oxidation method. The structure, property and functionality of the resulting NOCNF was 533 thoroughly characterized by SEM, TEM, AFM, FTIR, WAXD, TGA and DTG techniques. The 534 nitro-oxidation method appears to be a useful approach that can extract nanocellulose adsorbents 535 from many other raw biomass sources. The present mercury remediation study using NOCNF 536 comprises of three major activities to investigate (i) the adsorption mechanism of NOCNF in 537 suspension against $\mathrm{Hg}^{2+}$ ions; (2) the effects of $\mathrm{pH}$ and time on the adsorption capacity and removal 538 efficiency of $\mathrm{Hg}^{2+}$ by NOCNF; and (3) the deployment of NOCNF suspension as an 539 adsorbent/coagulant system, and of solid NOCNF adsorbent in filtration column. In the mechanism 540 study, it was found that at low $\mathrm{Hg}^{2+}$ concentrations $(<250 \mathrm{ppm})$, the removal mechanism was 541 dominated by electrostatic interactions between $\mathrm{Hg}^{2+}$ and $\mathrm{COO}^{-}$on the NOCNF surface; at high $542 \mathrm{Hg}^{2+}$ concentrations (> $1000 \mathrm{ppm}$ ), the removal mechanism was dominated by the mineralization 543 process of $\mathrm{HgO}$ crystal formation in the NOCNF scaffold. As a result of the mineralization, the 
544 maximum adsorption capability of NOCNF for the $\mathrm{Hg}^{2+}$ removal at $\mathrm{pH}=7$ was $257.07 \mathrm{mg} / \mathrm{g}$,

545 which was the highest among all mercury adsorbents reported thus far. Finally, we observed that

546 the removal efficiency by the NOCNF suspension was higher than that of the solid NOCNF

547 adsorbent in filtration column as expected. However, the practical depolyment value for each

548 system will depend on the detailed techno-economic assessment of the technology that is also

549 location dependent.

550

551 Acknowledgement

552

553 The financial support for this work was provided by a grant from the Polymer Program of the

554 Division of Materials Science in the National Science Foundation (DMR-1808690). The authors

555 thank Drs. Chung-Chueh Chang and Yuan Xue at the Advanced Energy Research and Technology

556 Center in Stony Brook University for the assistance of the TGA, TEM and AFM measurements,

557 and Ms. Katie Wooton at the Facility for Isotope Research and Student Training in Stony Brook

558 University for the assistance of the ICP-MS analysis.

559

560 


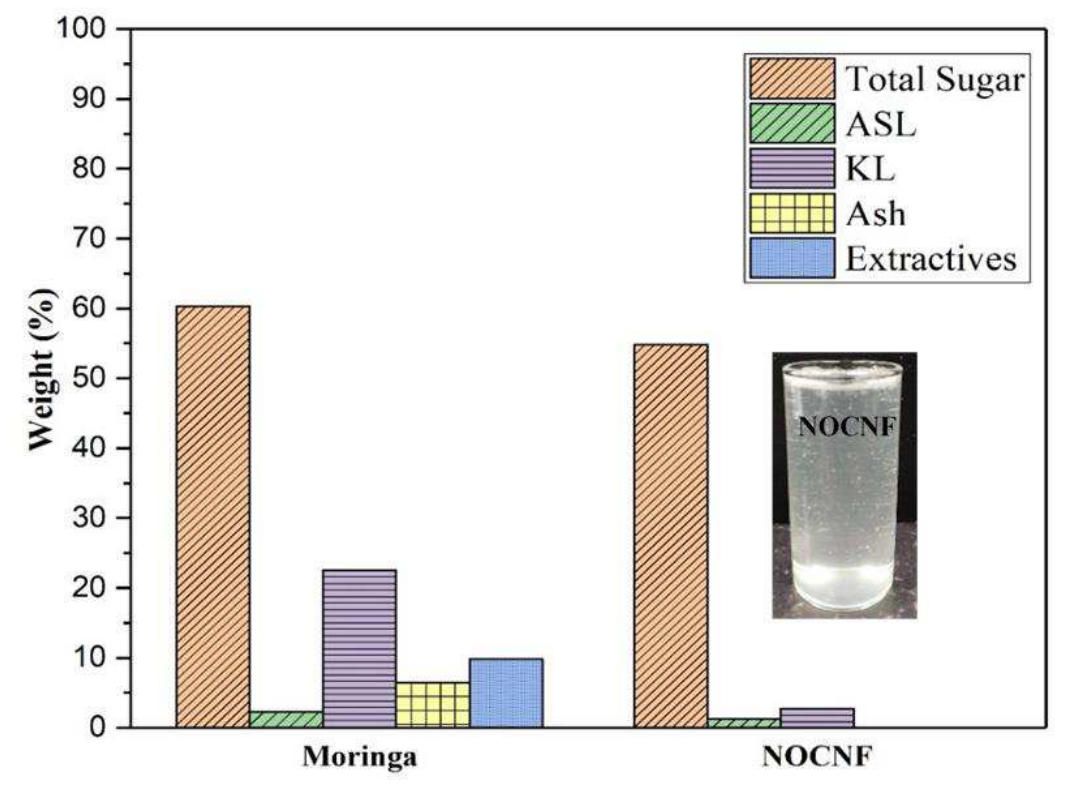

562 Figure 1. Chemical compositions of raw moringa and extracted NOCNF (ASL: acid soluable 563 lignin, KL: klason lignin). The inset image is the $0.4 \mathrm{wt} \mathrm{NOCNF}$ suspension that exhibits the 564 viscous and gel-like behavior).

565 


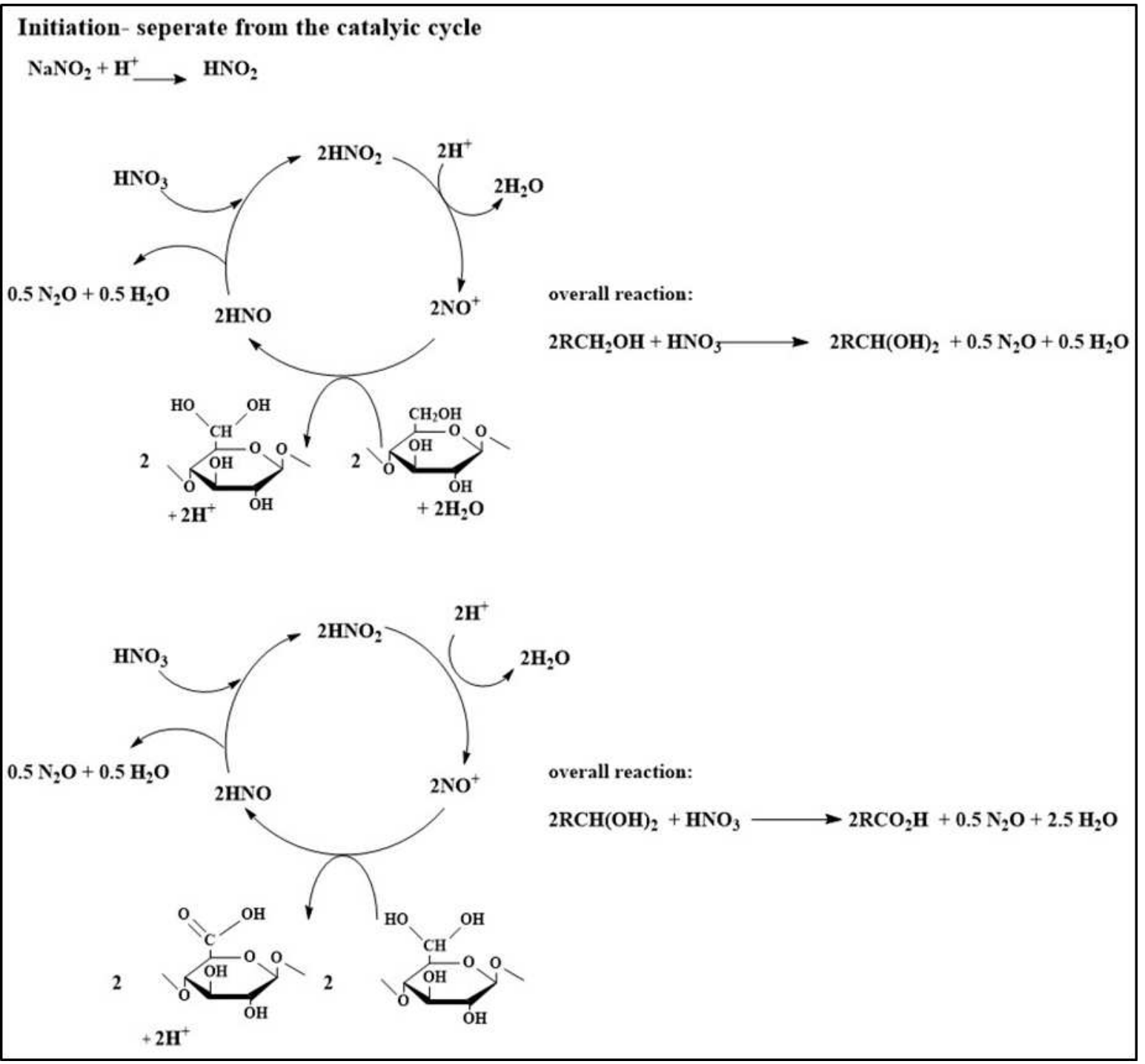

Figure 2. Proposed cellulose oxidation mechanisms by the nitro-oxidation method. 

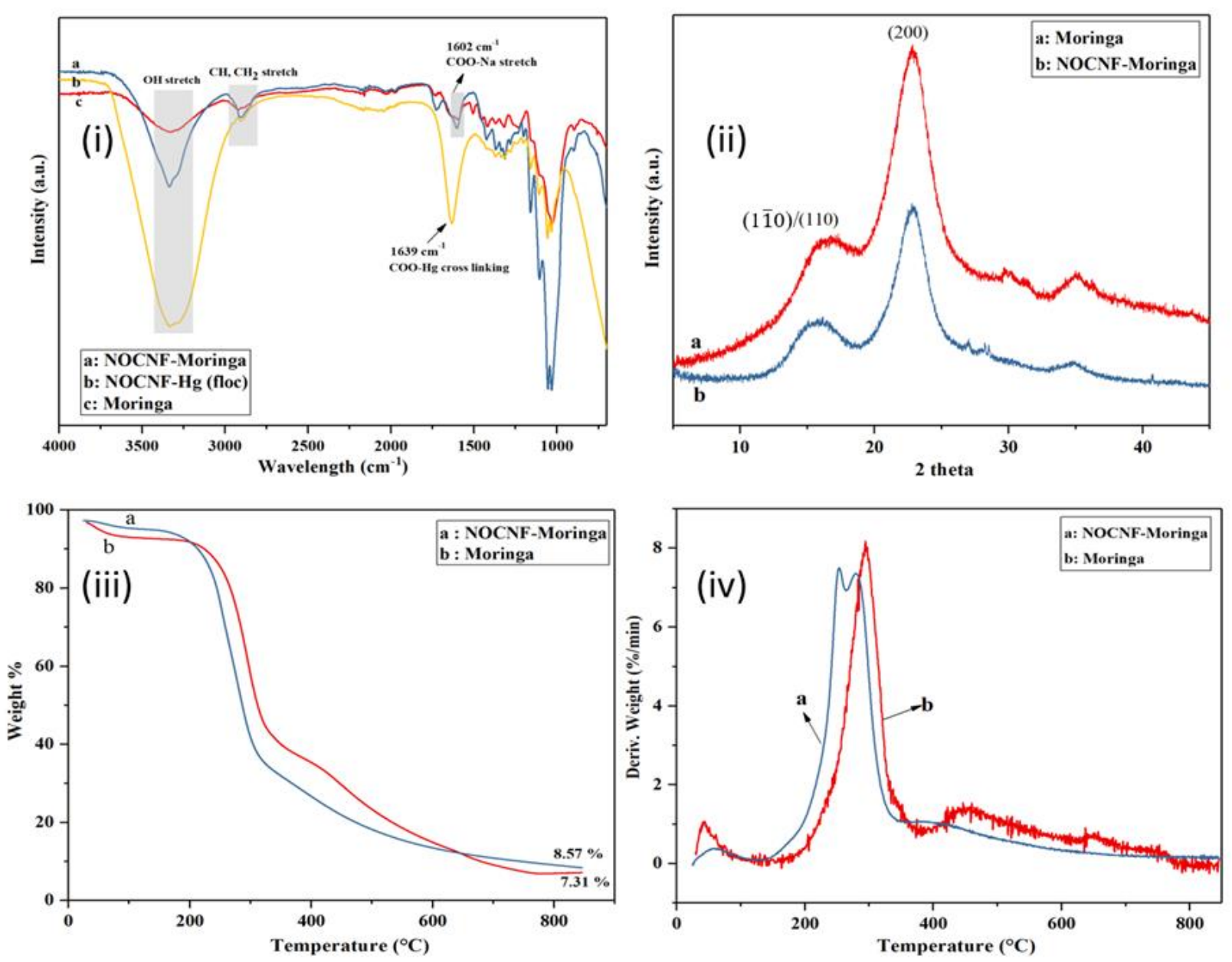

570 Figure 3. Characterization of raw moringa plant, NOCNF and NOCNF-Hg floc: (i) FTIR of raw

571 moringa plant (red curve), NOCNF (blue curve) and NOCNF-Hg floc (yellow curve); (ii)

572 WAXD paterns of raw moringa plant (red curve) and NOCNF (blue curve); (iii) TGA curves of

573 raw moringa plant (red curve) and NOCNF (blue curve); (iv) Derivative Thermogravimetric

574 (DTG) curve of raw moringa plant (red curve) and NOCNF (blue curve). 

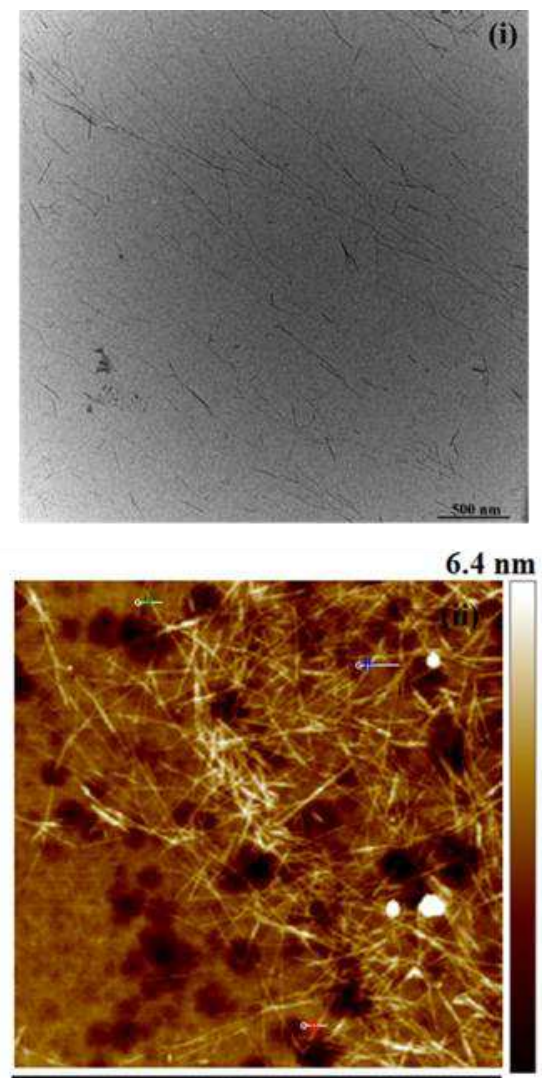

$2.5 \mu \mathrm{m}$

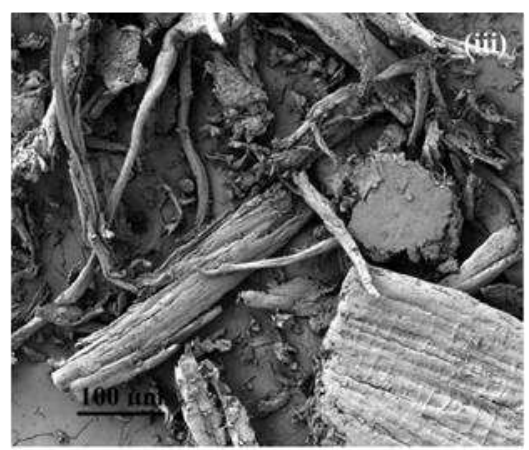

577 Figure 4. Morphological charcterization: (i) TEM and (ii) AFM images of NOCNF, (iii) SEM 578 image of crushed moringa fibers. 


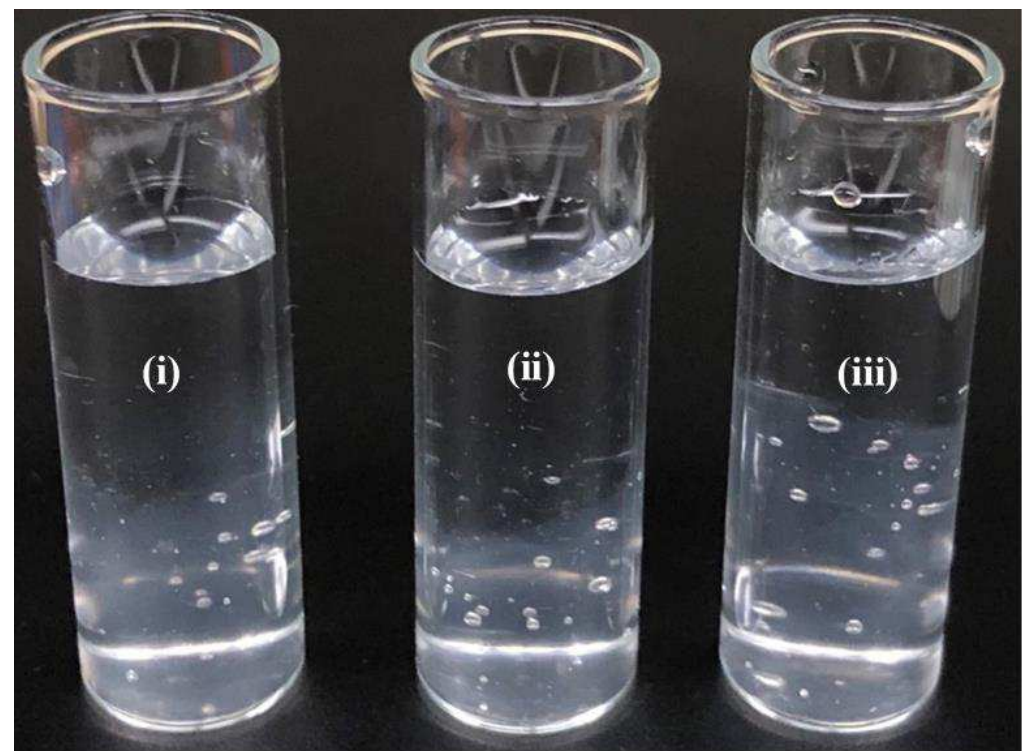

581 Figure 5. Photographs of suspensions NOCNF-Hg floc, formed by mixing of (i) 100 ppm, (ii) 582 $500 \mathrm{ppm}$ and (iii) $1000 \mathrm{ppm}$ of $\mathrm{Hg}^{2+}$ solutions with a $0.4 \mathrm{wt} \%$ NOCNF suspension. 

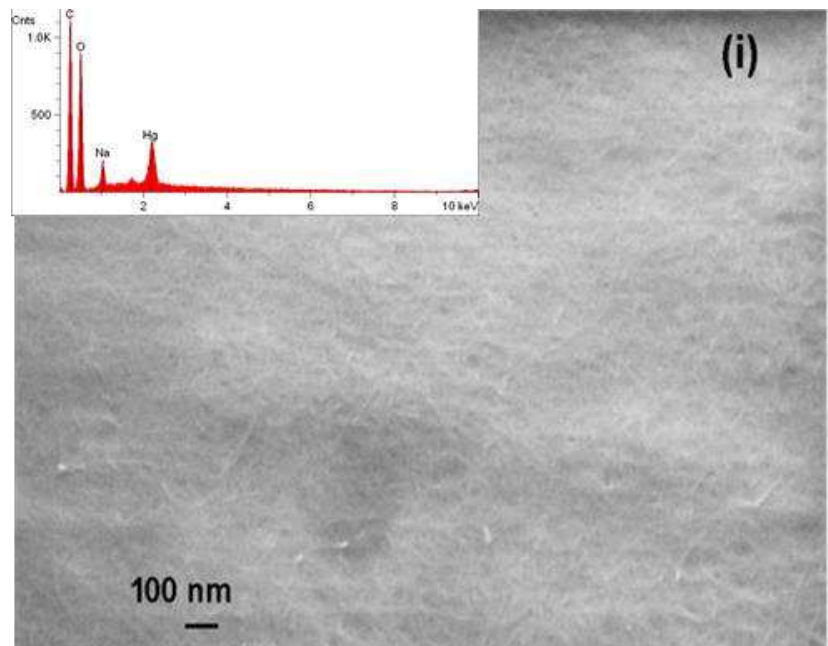

584

585 586

587

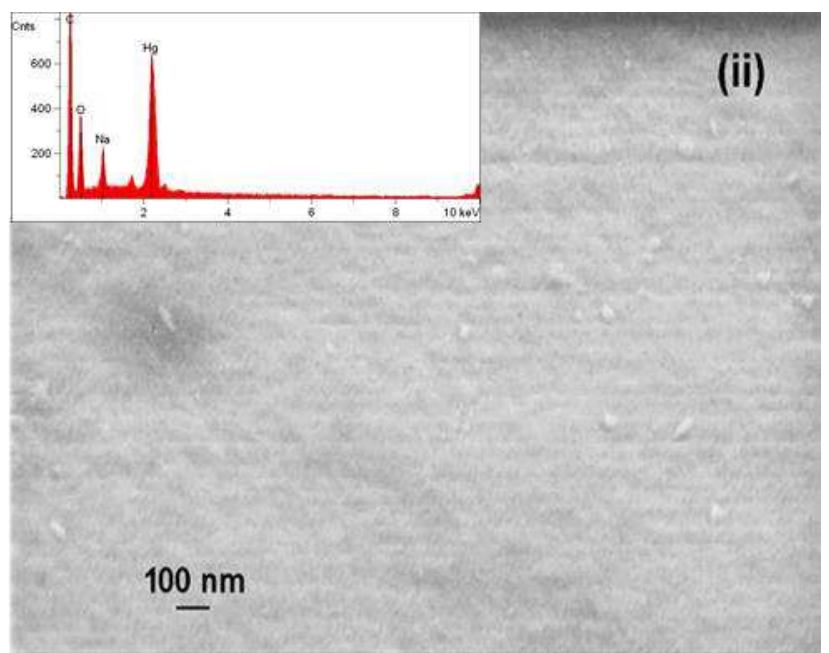

Figure 6. SEM images with EDS spectra (the insert) of NOCNF-Hg floc formed by using (i) 250 ppm and (ii) $1000 \mathrm{ppm}$ of $\mathrm{Hg}^{2+}$ solutions. 

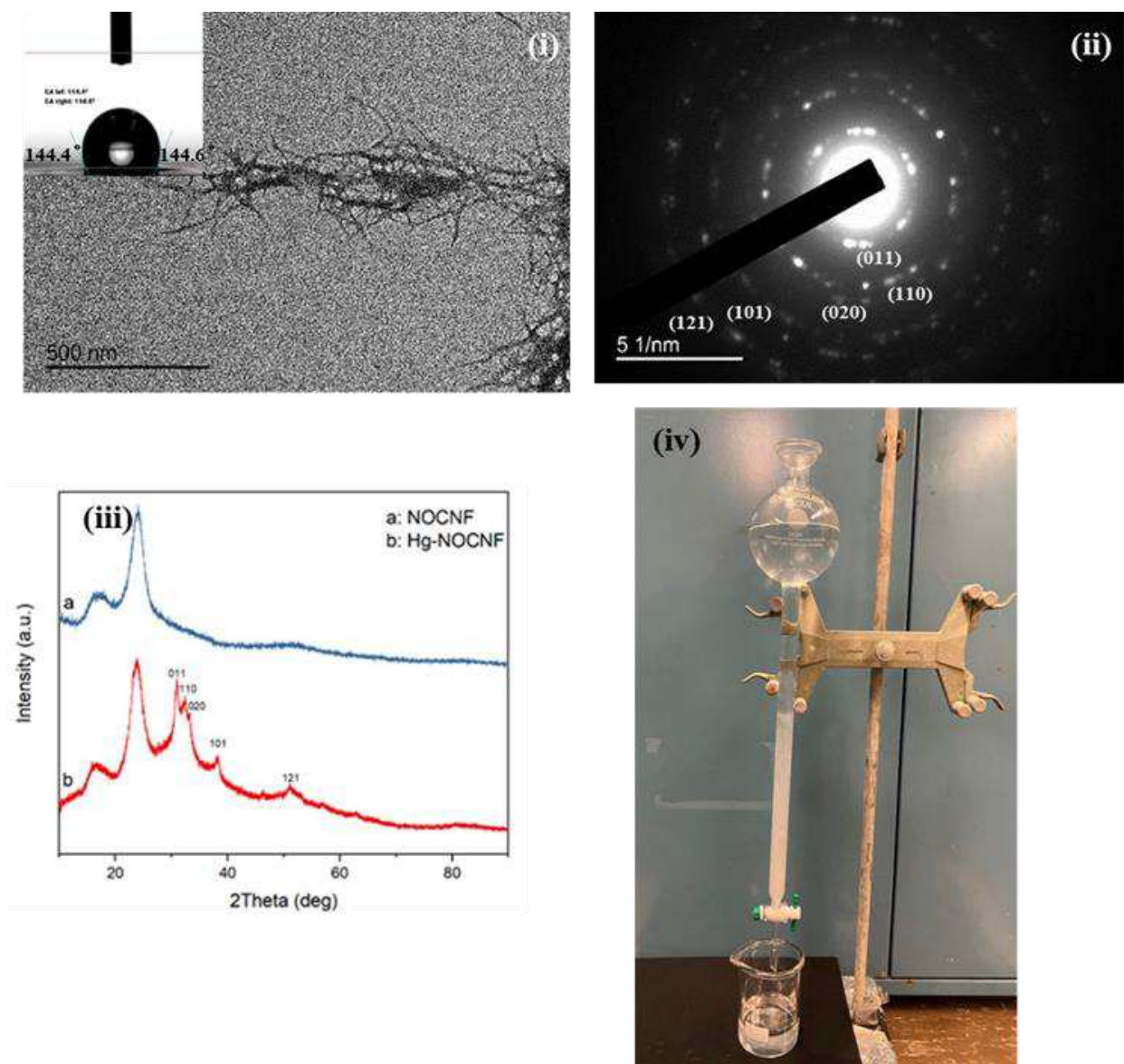

Figure 7. Characterization of the NOCNF-Hg floc: (i) TEM image of the floc; the inset 590 represents the contact angle of the floc, (ii) electron diffraction image of the floc, (iii) WAXD 591 profiles of NOCNF and NOCNF-Hg floc (formed by mixing of $0.32 \mathrm{wt} \%$ NOCNF suspension

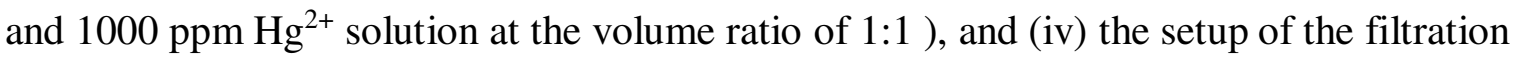
column. 

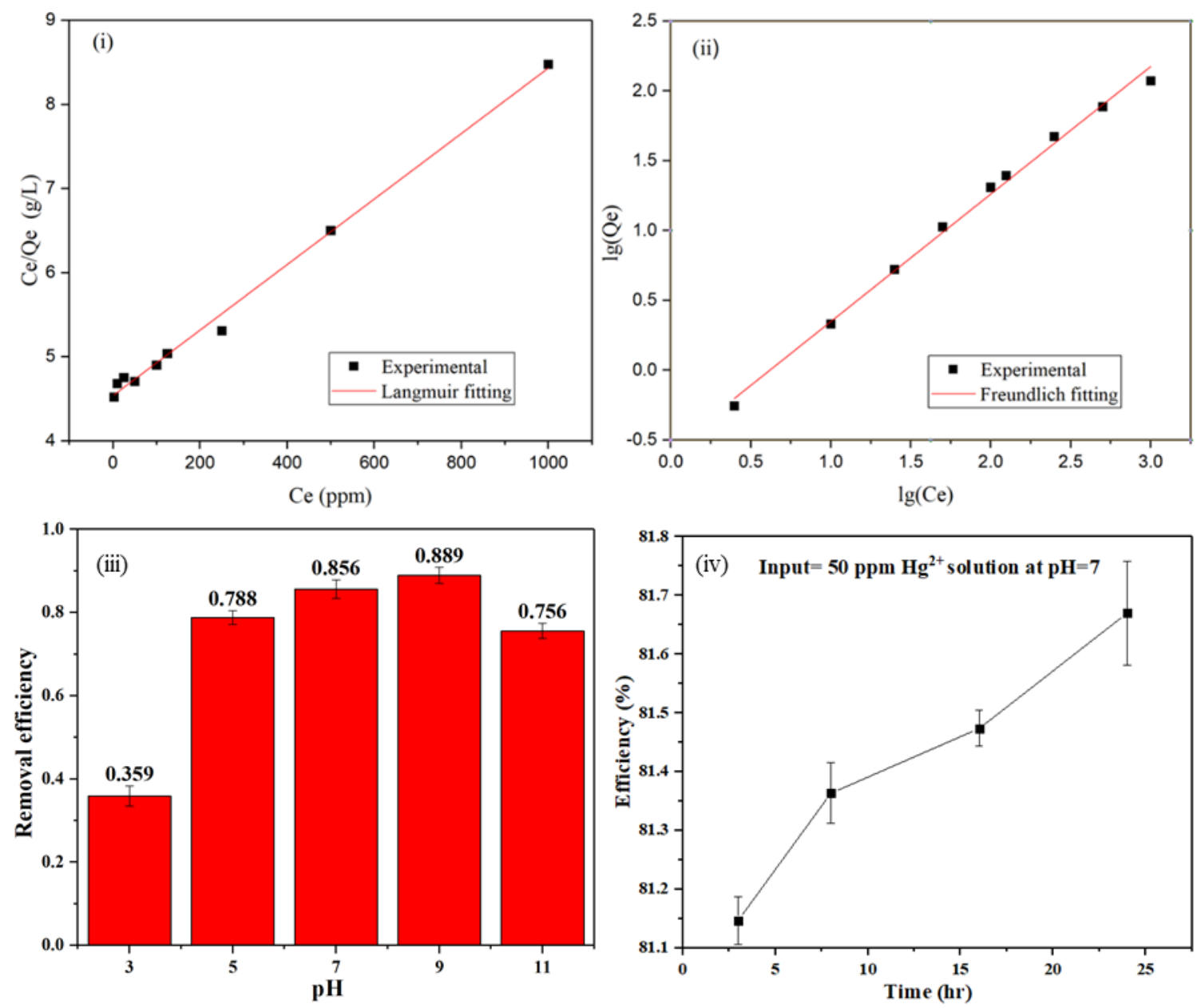

$597 \quad$ Figure 8. (i) The $\mathrm{Hg}^{2+}$ adsorption data by using the NOCNF suspension as an adsorbent (the $598 \mathrm{Hg}^{2+}$ concentration was ranged between 2.5 to $1000 \mathrm{ppm}$ ) analyzed by the Langmuir model, (ii) 599 the adsorption data analyzed by the Freudlich model, (iii) the effect of $\mathrm{pH}$ on the removal 600 efficiency and; (iv) the effect of time on the $\mathrm{Hg}^{2}$ removal efficiency by NOCNF at $100 \mathrm{ppm}^{\mathrm{Hg}} \mathrm{g}^{2+}$ 601 concentration at $\mathrm{pH}=7$. 
603

604

Table 1. Summary of the Langmuir and Freundlich fitting model parameters.

\begin{tabular}{|c|c|c|c|c|}
\hline & \multicolumn{2}{|c|}{ Langmuir } & \multicolumn{2}{c|}{ Freundlich } \\
\hline Equation & \multicolumn{2}{|c|}{$\mathrm{y}=0.00389 \mathrm{x}+4.538$} & \multicolumn{2}{c|}{$\mathrm{y}=0.91338 \mathrm{x}-0.565$} \\
\hline $\mathrm{R}^{2}$ & \multicolumn{2}{|c|}{0.9946} & \multicolumn{2}{c|}{0.9951} \\
\hline Parameters & $\boldsymbol{b}$ & $\boldsymbol{Q m} \mathbf{( m g / g )}$ & $\boldsymbol{n}$ & $\boldsymbol{K}_{\boldsymbol{f}}$ \\
\hline Value & 0.00086 & 257.07 & 1.095 & 3.673 \\
\hline
\end{tabular}

605

606 
Table 2. Comparison of the maximum adsorption capacity of varying adsorbents reported in the 608 literature and NOCNF in this study against the $\mathrm{Hg}^{2+}$ removal.

\begin{tabular}{|c|c|c|c|}
\hline Adsorbents & $\begin{array}{c}\text { Maximum } \\
\text { adsorption capacity } \\
Q m(\mathrm{mg} / \mathrm{g})\end{array}$ & $\begin{array}{c}\text { Adsorption range } \\
(\text { ppm })\end{array}$ & Reference \\
\hline $\begin{array}{l}\text { Thiol and hydroxyl } \\
\text { containing } \\
\text { montmorillonite }\end{array}$ & 8.57 & $<100$ & $\begin{array}{c}\text { [(Tran, Wu et al. } \\
\text { 2015)] }\end{array}$ \\
\hline $\begin{array}{c}\text { Nanoporous carbon } \\
\text { impregnated with } \\
\text { surfactants }\end{array}$ & 8.9 & $10-200$ & $\begin{array}{c}\text { [(Anbia and } \\
\text { Amirmahmoodi } \\
2016)]\end{array}$ \\
\hline MCM-41-NH-L & 152 & $100-800$ & $\begin{array}{c}\text { [(Puanngam and } \\
\text { Unob 2008)] }\end{array}$ \\
\hline Silica gel & 140 & $100-800$ & $\begin{array}{c}\text { [(Puanngam and } \\
\text { Unob 2008)] }\end{array}$ \\
\hline Coconut husk & 44.9 & $40-450$ & $\begin{array}{c}\text { [(Guo, Wang et al. } \\
\text { 2017)] }\end{array}$ \\
\hline $\begin{array}{c}\text { Activated carbon } \\
\text { from pistachio wood } \\
\text { waste }\end{array}$ & 202 & $2.5-45$ & $\begin{array}{c}\text { [(Sajjadi, } \\
\text { Mohammadzadeh et } \\
\text { al. 2018)] }\end{array}$ \\
\hline $\begin{array}{l}\text { Activated carbon } \\
\text { from bagasse pitch }\end{array}$ & 172 & $50-1000$ & $\begin{array}{l}\text { [(Anoop Krishnan } \\
\text { and Anirudhan } \\
\text { 2002)] }\end{array}$ \\
\hline $\begin{array}{l}\text { NOCNF from } \\
\text { moringa plant }\end{array}$ & 257.1 & $2.5-1000$ & This study \\
\hline
\end{tabular}


Table 3. Results from filtration column using NOCNF for $\mathrm{Hg}^{2+}$ removal.

613

\begin{tabular}{|c|c|c|c|c|}
\hline Column label & $\begin{array}{c}\text { Input concentration } \\
(\mathbf{p p m})\end{array}$ & $\begin{array}{c}\text { Filtrate ICP-MS } \\
\text { concentration } \\
(\mathbf{p p b})\end{array}$ & $\begin{array}{c}\text { Filtrate } \\
\text { concentration } \\
(\mathbf{p p m})\end{array}$ & Efficiency \\
\hline 1 & 100 & 25.7 & 25.70 & 0.743 \\
\hline 2 & 100 & 26.5 & 26.50 & 0.735 \\
\hline 3 & 100 & 31.1 & 31.10 & 0.689 \\
\hline 4 & 100 & 31.6 & 31.60 & 0.684 \\
\hline 5 & 100 & 33 & 33.00 & 0.670 \\
\hline 6 & 100 & 34.8 & 34.80 & 0.652 \\
\hline 7 & 100 & 35.5 & 35.50 & 0.645 \\
\hline 8 & 100 & 40.4 & 40.40 & 0.596 \\
\hline 9 & 100 & 42.5 & 42.50 & 0.575 \\
\hline 10 & 100 & 46.7 & 46.70 & 0.533 \\
\hline
\end{tabular}

614

615

616 
618 Anbia, M. and S. Amirmahmoodi (2016). "Removal of $\mathrm{Hg}$ (II) and $\mathrm{Mn}$ (II) from aqueous solution using

619 nanoporous carbon impregnated with surfactants." Arabian Journal of Chemistry 9: S319-S325.

620 Anoop Krishnan, K. and T. S. Anirudhan (2002). "Removal of mercury(II) from aqueous solutions and

621 chlor-alkali industry effluent by steam activated and sulphurised activated carbons prepared from

622 bagasse pith: kinetics and equilibrium studies." Journal of Hazardous Materials 92(2): 161-183.

623 Baeyens, W. R. G., R. Ebinghaus, O. F. Vasil'ev, N. A. R. W. o. Regional, F. Global Mercury Cycles: Sources

624

625

626

627

628

629

630

631

632

633

634

635

636

637

638

639

640

641

642

643

644

645

646

647

648

649

650

651

652

653

654

655

656

657

658 and B. Mass (1997). "Global and regional mercury cycles : sources, fluxes and mass balances."

Chen, H., S. K. Sharma, P. R. Sharma, H. Yeh, K. Johnson and B. S. Hsiao (2019). "Arsenic(III) Removal by Nanostructured Dialdehyde Cellulose-Cysteine Microscale and Nanoscale Fibers." ACS Omega 4(26): 22008-22020.

Chi, K. and J. M. Catchmark (2017). "The influences of added polysaccharides on the properties of bacterial crystalline nanocellulose." Nanoscale 9(39): 15144-15158.

Chiarle, S., M. Ratto and M. Rovatti (2000). "Mercury removal from water by ion exchange resins adsorption." Water Research 34(11): 2971-2978.

Cui, G., M. Liu, Y. Chen, W. Zhang and J. Zhao (2016). "Synthesis of a ferric hydroxide-coated cellulose nanofiber hybrid for effective removal of phosphate from wastewater." Carbohydrate Polymers 154: 4047.

Di Natale, F., A. Erto, A. Lancia and D. Musmarra (2011). "Mercury adsorption on granular activated carbon in aqueous solutions containing nitrates and chlorides." Journal of Hazardous Materials 192(3): 1842-1850.

Guo, Y., Z. Wang, X. Zhou and R. Bai (2017). "Removal of mercury (II) from aqueous solution with three commercial raw activated carbons." Research on Chemical Intermediates 43(4): 2273-2297.

Harada, M. (1995). "Minamata Disease: Methylmercury Poisoning in Japan Caused by Environmental Pollution." Critical Reviews in Toxicology 25(1): 1-24.

International Symposium on Metals Speciation, S., Recovery, J. W. Patterson, R. Passino, C. Industrial

Waste Elimination Research and a. Istituto di ricerca sulle Metals speciation, separation, and recovery, Chelsea, MI, Lewis Publishers.

Kalibbala, H., O. Wahlberg and T. Hawumba (2009). "The impact of Moringa oleifera as a coagulant aid on the removal of trihalomethane (THM) precursors and iron from drinking water." Water Science and Technology: Water Supply 9(6): 707-714.

Kim, J.-H., B. S. Shim, H. S. Kim, Y.-J. Lee, S.-K. Min, D. Jang, Z. Abas and J. Kim (2015). "Review of nanocellulose for sustainable future materials." International Journal of Precision Engineering and Manufacturing-Green Technology 2(2): 197-213.

Lai, E. P. C., B. Wong and V. A. VanderNoot (1993). "Preservation of solid mercuric dithizonate samples with polyvinyl chloride for determination of mercury(II) in environmental waters by photochromisminduced photoacoustic spectrometry." Talanta 40(7): 1097-1105.

Larson, K. A. and J. M. Wiencek (1992). "Liquid ion exchange for mercury removal from water over a wide pH range." Industrial \& Engineering Chemistry Research 31(12): 2714-2722.

Liu, P., K. Oksman and A. P. Mathew (2016). "Surface adsorption and self-assembly of Cu(II) ions on TEMPO-oxidized cellulose nanofibers in aqueous media." Journal of Colloid and Interface Science 464: 175-182.

659 Melesse, A. and K. Berihun (2013). "Chemical and mineral compositions of pods of Moringa stenopetala 660 and Moringa oleifera cultivated in the lowland of Gamogofa Zone." Journal of Environmental and 661 Occupational Science 2: 1. 
Mohadesi, A., M. Ranjbar and S. M. Hosseinpour-Mashkani (2014). "Solvent-free synthesis of mercury oxide nanoparticles by a simple thermal decomposition method." Superlattices and Microstructures 66 : 48-53.

Nam, K. H., S. Gomez-Salazar and L. L. Tavlarides (2003). "Mercury(II) Adsorption from Wastewaters Using a Thiol Functional Adsorbent." Industrial \& Engineering Chemistry Research 42(9): 1955-1964. Ornaghi Júnior, H. L., A. J. Zattera and S. C. Amico (2014). "Thermal behavior and the compensation effect of vegetal fibers." Cellulose 21(1): 189-201.

Puanngam, M. and F. Unob (2008). "Preparation and use of chemically modified MCM-41 and silica gel as selective adsorbents for $\mathrm{Hg}(\mathrm{II})$ ions." Journal of Hazardous Materials 154(1): 578-587.

Rio, S. and A. Delebarre (2003). "Removal of mercury in aqueous solution by fluidized bed plant fly ash." Fuel 82(2): 153-159.

Sajjadi, S.-A., A. Mohammadzadeh, H. N. Tran, I. Anastopoulos, G. L. Dotto, Z. R. Lopičić, S. Sivamani, A. Rahmani-Sani, A. Ivanets and A. Hosseini-Bandegharaei (2018). "Efficient mercury removal from wastewater by pistachio wood wastes-derived activated carbon prepared by chemical activation using a novel activating agent." Journal of Environmental Management 223: 1001-1009.

Sehaqui, H., A. Mautner, U. Perez de Larraya, N. Pfenninger, P. Tingaut and T. Zimmermann (2016).

"Cationic cellulose nanofibers from waste pulp residues and their nitrate, fluoride, sulphate and phosphate adsorption properties." Carbohydrate Polymers 135: 334-340. Sharma, P., A. Chattopadhyay, C. Zhan, S. Sharma, L. Geng and B. Hsiao (2018). "Lead removal from water using carboxycellulose nanofibers prepared by nitro-oxidation method." Cellulose 25. Sharma, P. R., A. Chattopadhyay, S. K. Sharma, L. Geng, N. Amiralian, D. Martin and B. S. Hsiao (2018). "Nanocellulose from Spinifex as an Effective Adsorbent to Remove Cadmium(II) from Water." ACS Sustainable Chemistry \& Engineering 6(3): 3279-3290. Sharma, P. R., A. Chattopadhyay, S. K. Sharma and B. S. Hsiao (2017). "Efficient Removal of UO22+ from Water Using Carboxycellulose Nanofibers Prepared by the Nitro-Oxidation Method." Industrial \& Engineering Chemistry Research 56(46): 13885-13893.

Sharma, P. R., R. Joshi, S. K. Sharma and B. S. Hsiao (2017). "A Simple Approach to Prepare Carboxycellulose Nanofibers from Untreated Biomass." Biomacromolecules 18(8): 2333-2342.

Sharma, P. R., S. K. Sharma, W. Borges, H. Chen and B. S. Hsiao (2020). Remediation of UO<sub $>2</$ sub $>$ $<$ sup $>2+</$ sup $>$ from Water by Nitro-Oxidized Carboxycellulose Nanofibers: Performance and Mechanism. Contaminants in Our Water: Identification and Remediation Methods, American Chemical Society. 1352: 269-283.

Sharma, P. R. and A. J. Varma (2014). "Functionalized celluloses and their nanoparticles: morphology, thermal properties, and solubility studies." Carbohydrate polymers 104: 135-142.

Sharma, P. R. and A. J. Varma (2014). "Thermal stability of cellulose and their nanoparticles: Effect of incremental increases in carboxyl and aldehyde groups." Carbohydrate Polymers 114: 339-343. Sharma, P. R., B. Zheng, S. K. Sharma, C. Zhan, R. Wang, S. R. Bhatia and B. S. Hsiao (2018). "High Aspect Ratio Carboxycellulose Nanofibers Prepared by Nitro-Oxidation Method and Their Nanopaper Properties." ACS Applied Nano Materials 1(8): 3969-3980. Sharma, S. K., P. R. Sharma, H. Chen, K. Johnson, C. Zhan, R. Wang and B. Hsiao (2020). CelluloseSupported Nanosized Zinc Oxide: Highly Efficient Bionanomaterial for Removal of Arsenic from Water. Contaminants in Our Water: Identification and Remediation Methods, American Chemical Society. 1352: 253-267.

Sharma, S. K., P. R. Sharma, S. Lin, H. Chen, K. Johnson, R. Wang, W. Borges, C. Zhan and B. S. Hsiao (2020). "Reinforcement of Natural Rubber Latex Using Jute Carboxycellulose Nanofibers Extracted Using Nitro-Oxidation Method." Nanomaterials 10(4): 706. 
Skubal, L. R. and N. K. Meshkov (2002). "Reduction and removal of mercury from water using argininemodified TiO2." Journal of Photochemistry and Photobiology A: Chemistry 148(1): 211-214. Sluiter, A., B. Hames, R. Ruiz, C. Scarlata, J. Sluiter, D. Templeton and D. Crocker (2010). "Determination of structural carbohydrates and lignin in biomass." Laboratory analytical procedure(TP-510-42618). Strojny, E. J., R. Iwamasa and L. K. Frevel (1971). "Oxidation of 2-methoxyethanol to methoxyacetic acid by nitric acid solutions." Journal of the American Chemical Society 93(5): 1171-1178. Suman, A. Kardam, M. Gera and V. K. Jain (2015). "A novel reusable nanocomposite for complete removal of dyes, heavy metals and microbial load from water based on nanocellulose and silver nanoembedded pebbles." Environmental Technology 36(6): 706-714.

Thakur, V. K. and S. I. Voicu (2016). "Recent advances in cellulose and chitosan based membranes for water purification: A concise review." Carbohydrate Polymers 146: 148-165.

Tran, L., P. Wu, Y. Zhu, S. Liu and N. Zhu (2015). "Comparative study of Hg(II) adsorption by thiol- and hydroxyl-containing bifunctional montmorillonite and vermiculite." Applied Surface Science 356: 91-101. Wang, D. (2019). "A critical review of cellulose-based nanomaterials for water purification in industrial processes." Cellulose 26(2): 687.

Wang, J.-W. and Y.-M. Kuo (2007). "Preparation of fructose - mediated (polyethylene glycol/chitosan) membrane and adsorption of heavy metal ions." Journal of Applied Polymer Science 105: 1480-1489. Wang, R., S. Guan, A. Sato, X. Wang, Z. Wang, R. Yang, B. S. Hsiao and B. Chu (2013). "Nanofibrous microfiltration membranes capable of removing bacteria, viruses and heavy metal ions." Journal of Membrane Science 446: 376-382.

Wang, X. and L. Andrews (2005). "Infrared Spectrum of $\mathrm{Hg}(\mathrm{OH}) 2$ in Solid Neon and Argon." Inorganic Chemistry 44(1): 108-113.

Zabihi, M., A. Ahmadpour and A. H. Asl (2009). "Removal of mercury from water by carbonaceous sorbents derived from walnut shell." Journal of Hazardous Materials 167(1): 230-236. Zhang, F.-S., J. O. Nriagu and H. Itoh (2005). "Mercury removal from water using activated carbons derived from organic sewage sludge." Water Research 39(2): 389-395.

Zhang, X., Z. Zhao, G. Ran, Y. Liu, S. Liu, B. Zhou and Z. Wang (2013). "Synthesis of lignin-modified silica nanoparticles from black liquor of rice straw pulping." Powder Technology 246: 664-668.

Zhu, C., I. Dobryden, J. Rydén, S. Öberg, A. Holmgren and A. P. Mathew (2015). "Adsorption Behavior of Cellulose and Its Derivatives toward Ag(I) in Aqueous Medium: An AFM, Spectroscopic, and DFT Study." Langmuir 31(45): 12390-12400. 
Figures

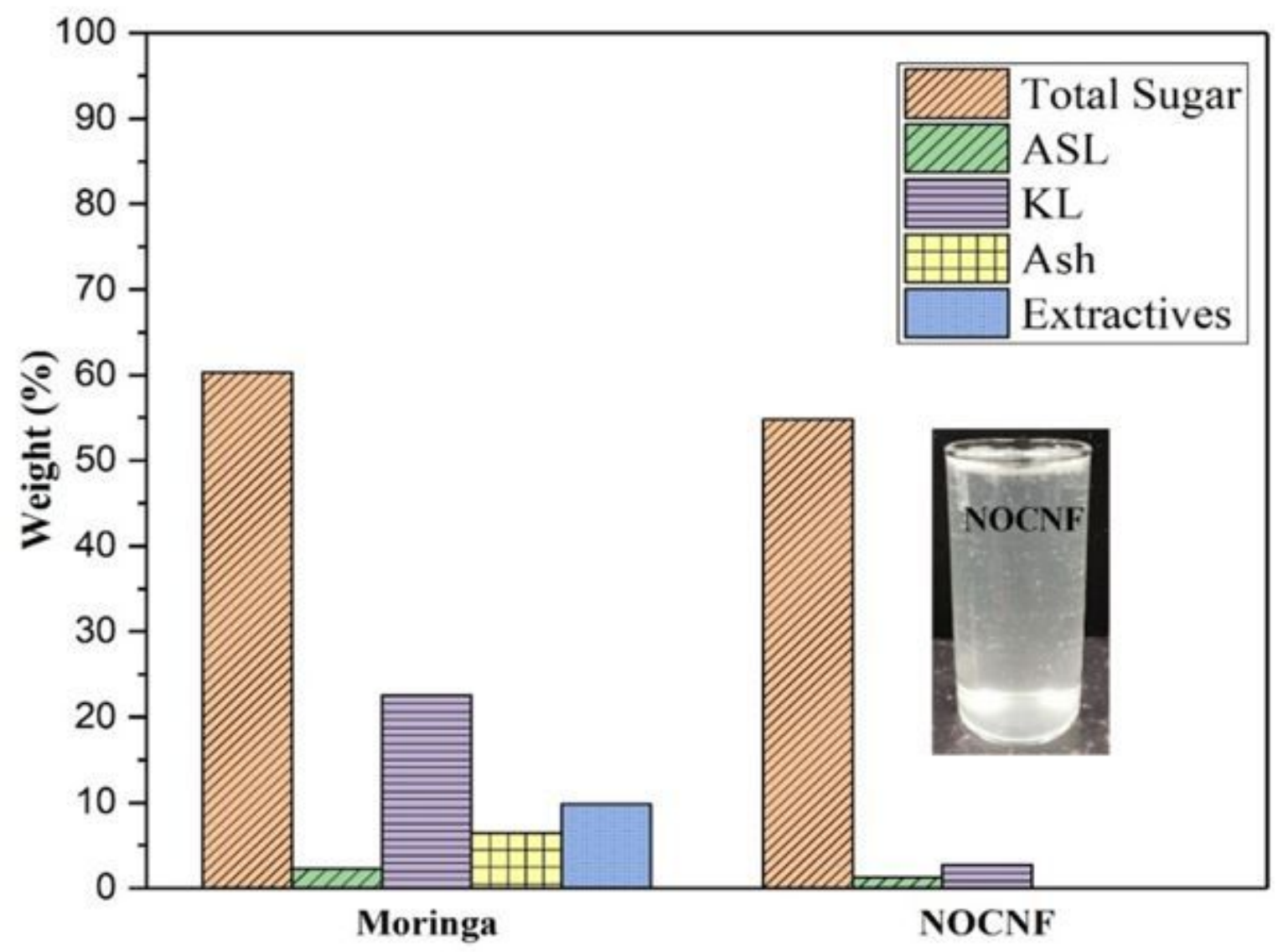

Figure 1

Chemical compositions of raw moringa and extracted NOCNF (ASL: acid soluable lignin, KL: klason lignin). The inset image is the 0.4 wt NOCNF suspension that exhibits the viscous and gel-like behavior). 


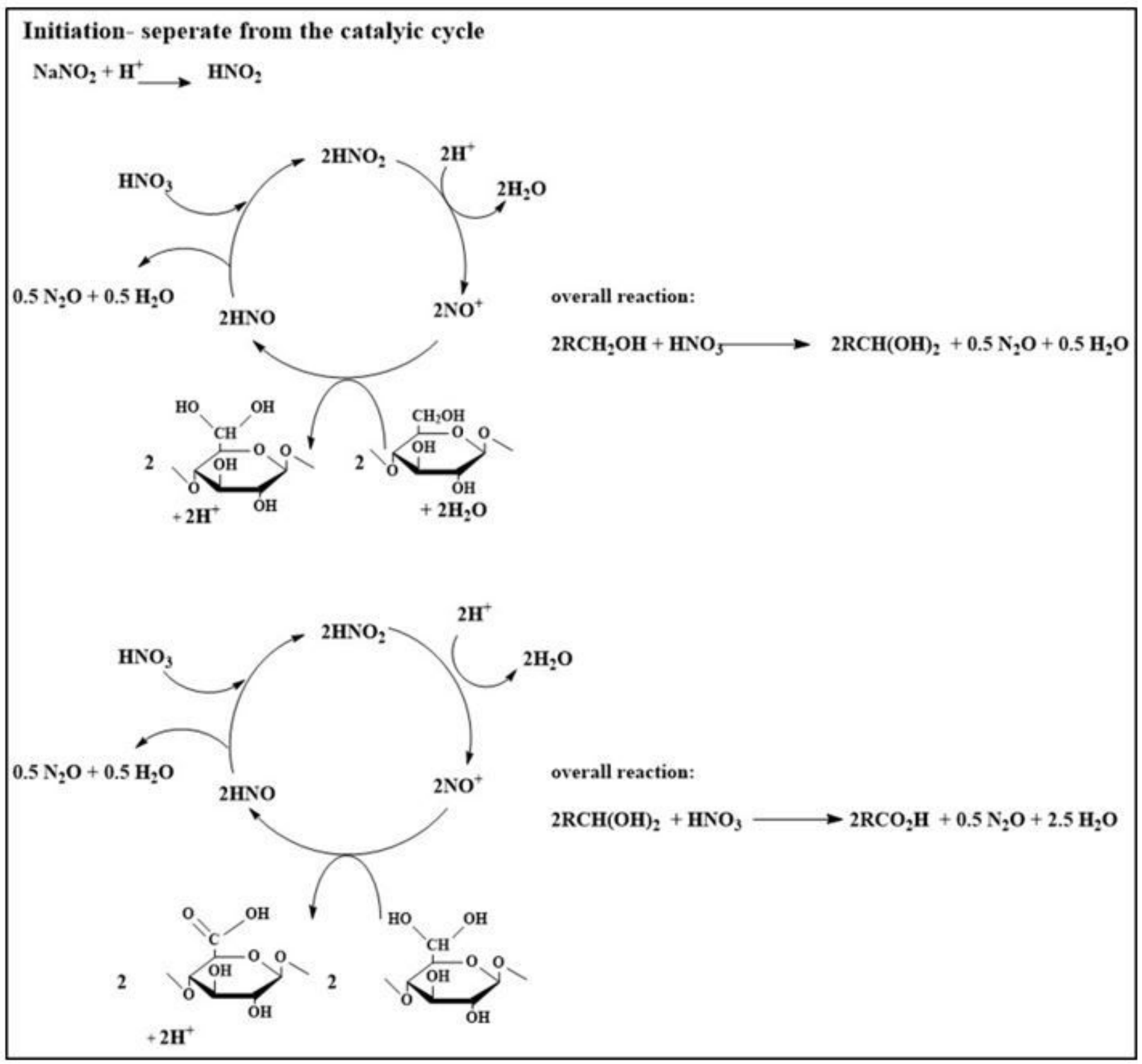

Figure 2

Proposed cellulose oxidation mechanisms by the nitro-oxidation method. 

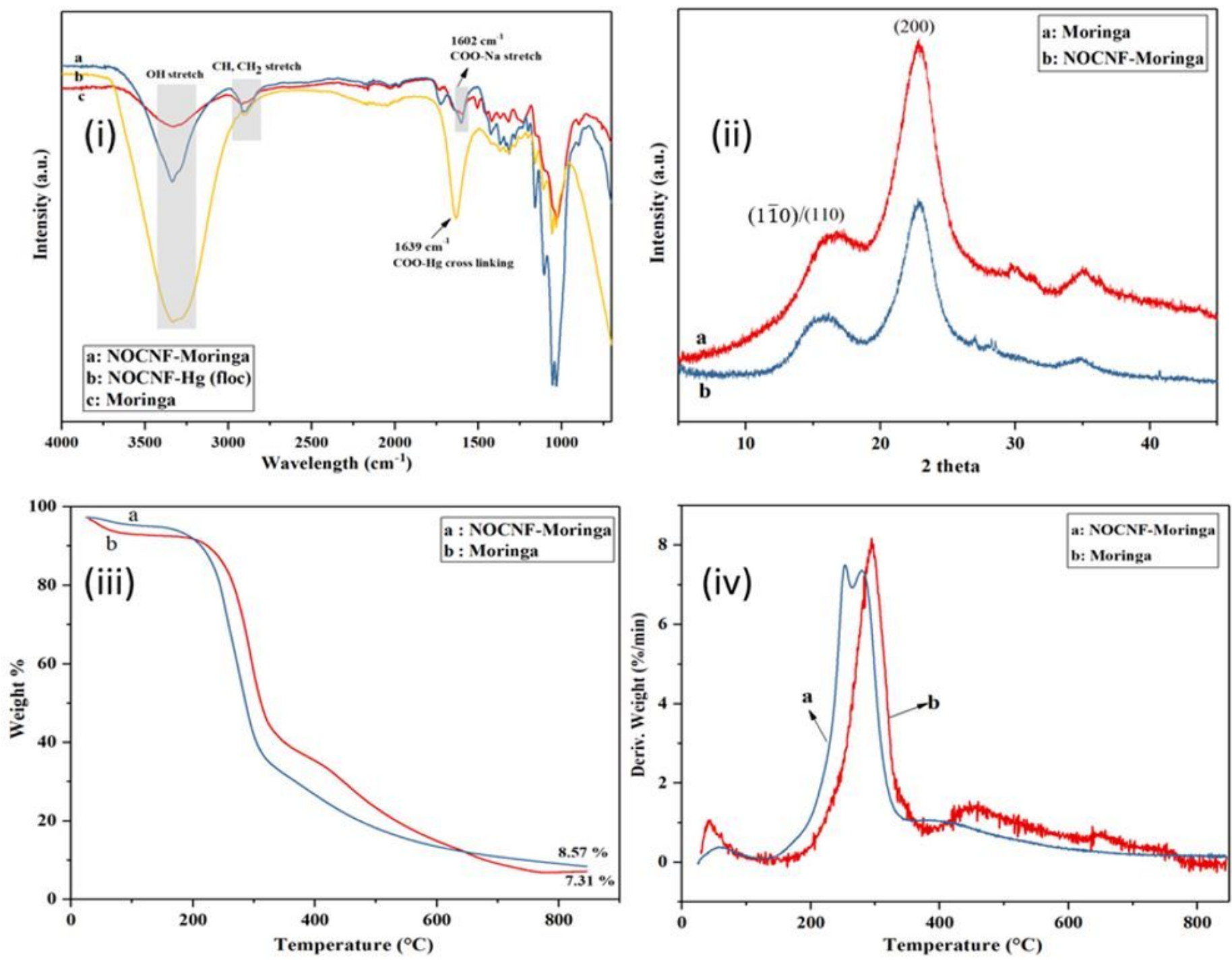

Figure 3

Characterization of raw moringa plant, NOCNF and NOCNF-Hg floc: (i) FTIR of raw moringa plant (red curve), NOCNF (blue curve) and NOCNF-Hg floc (yellow curve); (ii) WAXD paterns of raw moringa plant (red curve) and NOCNF (blue curve); (iii) TGA curves of raw moringa plant (red curve) and NOCNF (blue curve); (iv) Derivative Thermogravimetric (DTG) curve of raw moringa plant (red curve) and NOCNF (blue curve). 

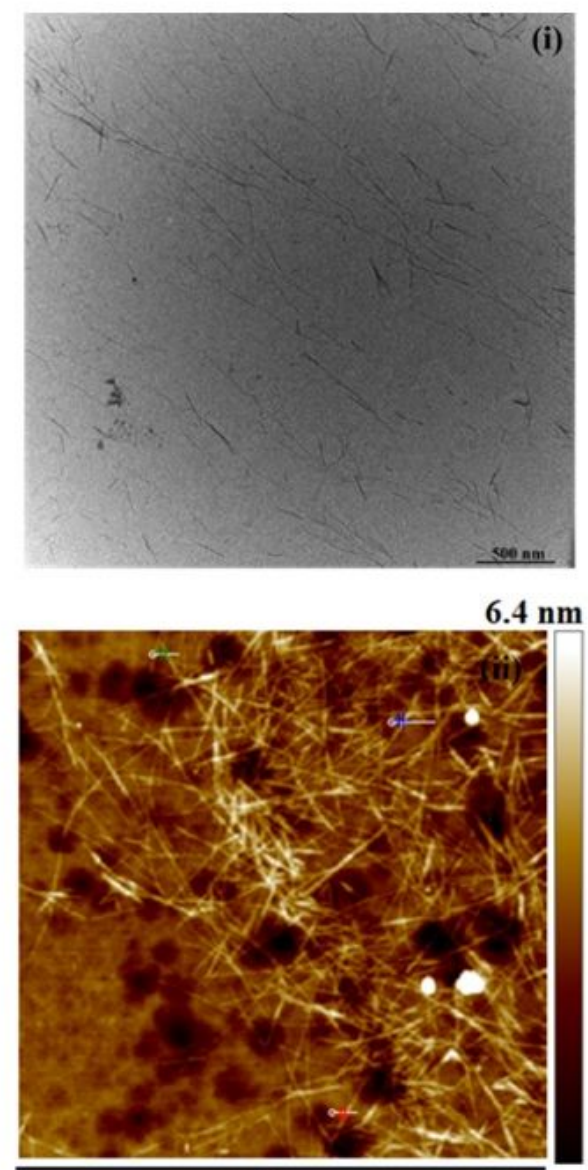

$2.5 \mu \mathrm{m}$

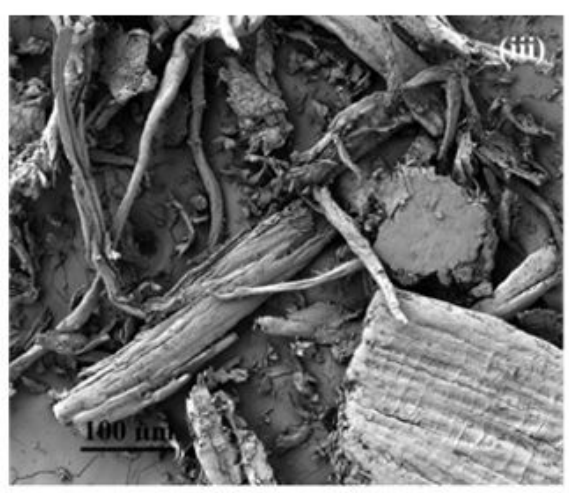

\section{Figure 4}

Morphological charcterization: (i) TEM and (ii) AFM images of NOCNF, (iii) SEM image of crushed moringa fibers. 


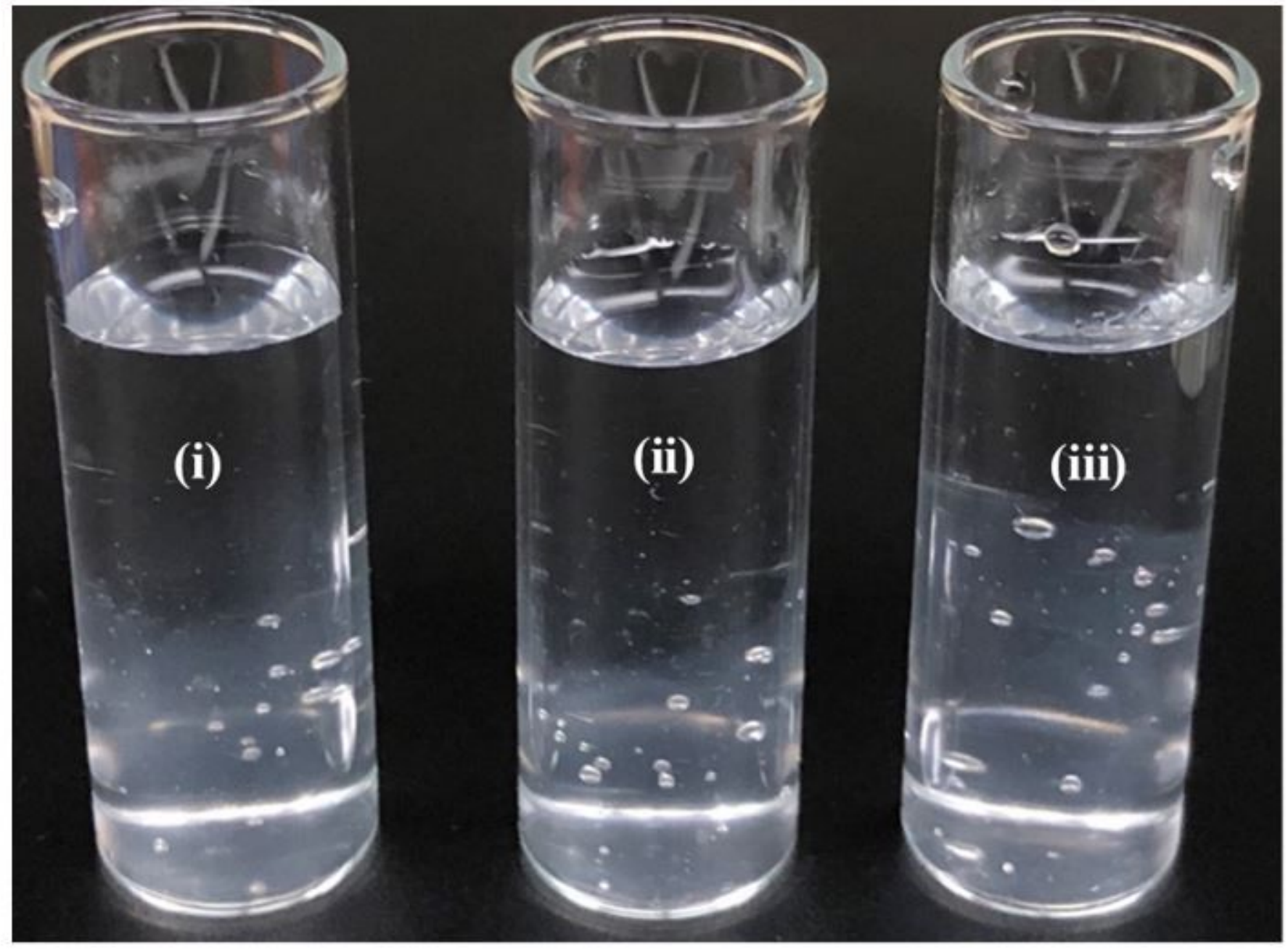

Figure 5

Photographs of suspensions NOCNF-Hg floc, formed by mixing of (i) 100 ppm, (ii) 500 ppm and (iii) 1000 ppm of $\mathrm{Hg} 2+$ solutions with a $0.4 \mathrm{wt} \%$ NOCNF suspension. 

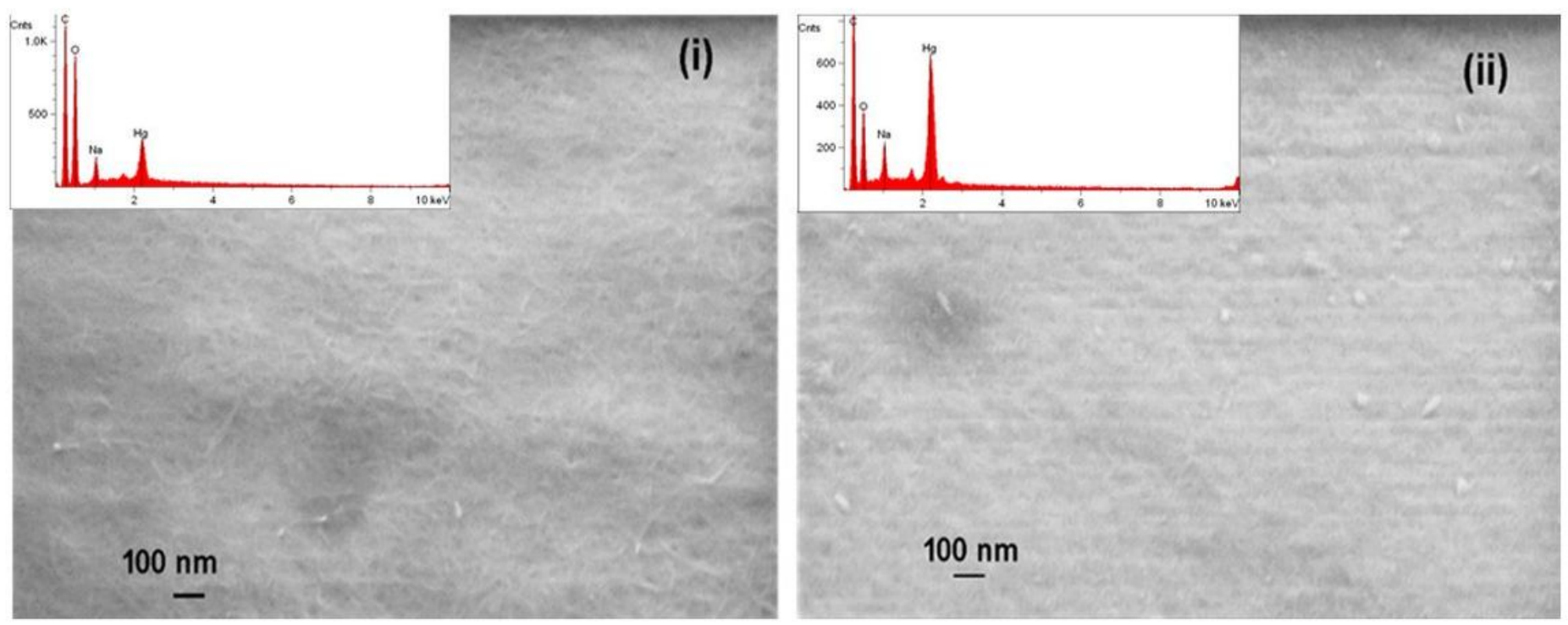

Figure 6

SEM images with EDS spectra (the insert) of NOCNF-Hg floc formed by using (i) $250 \mathrm{ppm}$ and (ii) 1000 ppm of Hg2+ solutions. 

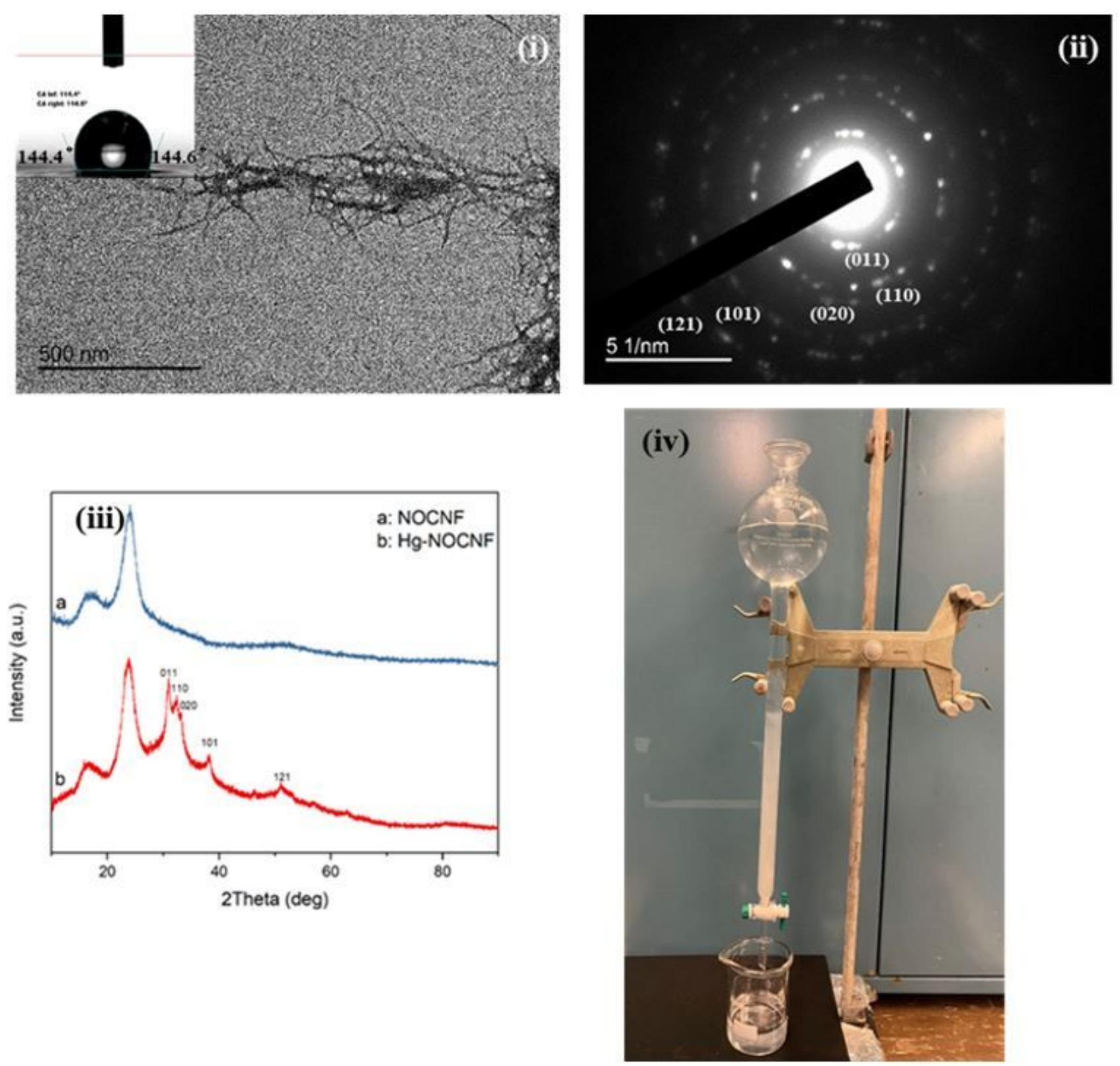

\section{Figure 7}

Characterization of the NOCNF-Hg floc: (i) TEM image of the floc; the inset represents the contact angle of the floc, (ii) electron diffraction image of the floc, (iii) WAXD profiles of NOCNF and NOCNF-Hg floc (formed by mixing of $0.32 \mathrm{wt} \%$ NOCNF suspension and $1000 \mathrm{ppm} \mathrm{Hg} 2+$ solution at the volume ratio of $1: 1$ ), and (iv) the setup of the filtration column. 

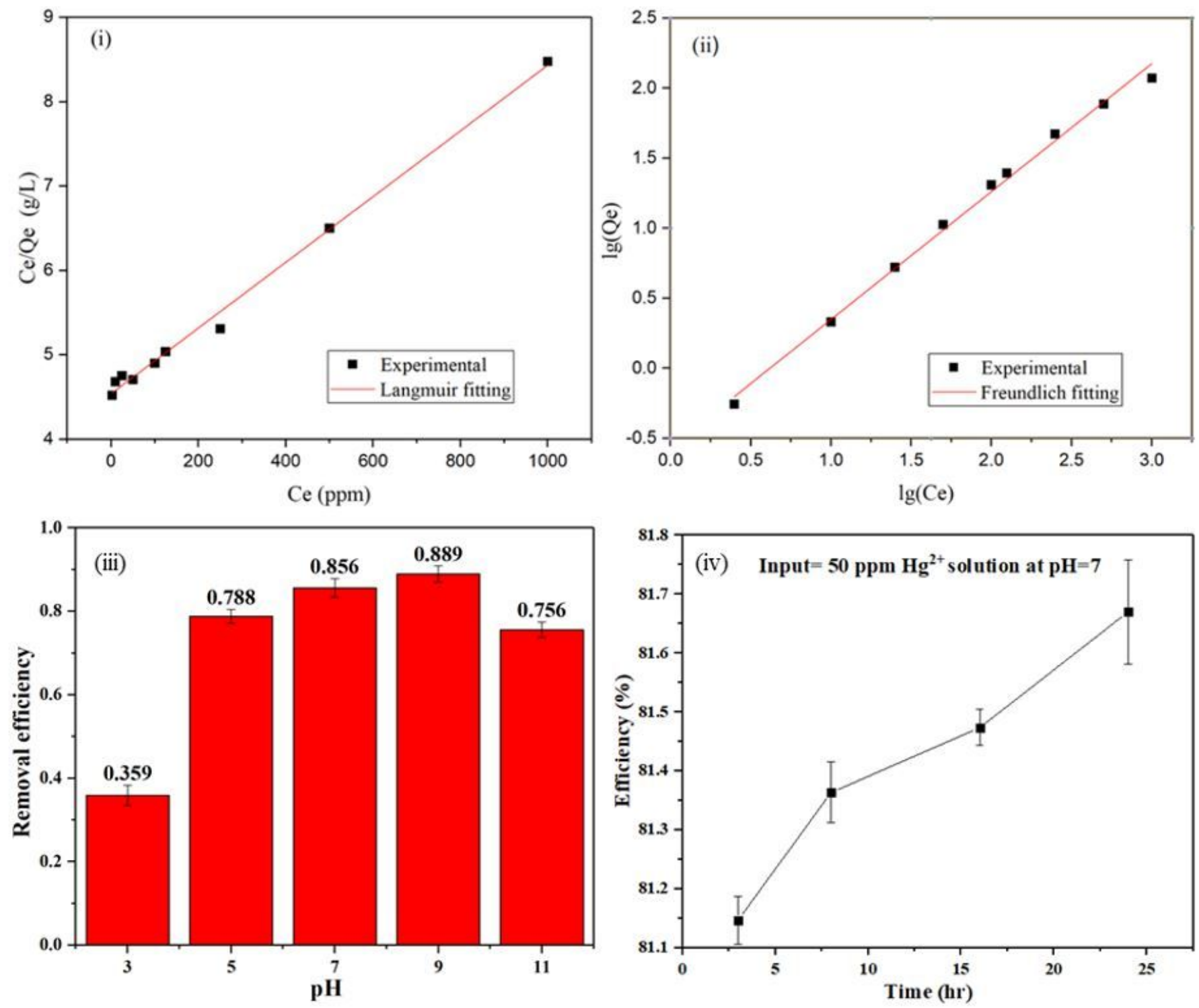

Figure 8

(i) The Hg2+ adsorption data by using the NOCNF suspension as an adsorbent (the $\mathrm{Hg} 2+$ concentration was ranged between 2.5 to $1000 \mathrm{ppm}$ ) analyzed by the Langmuir model, (ii) the adsorption data analyzed by the Freudlich model, (iii) the effect of $\mathrm{pH}$ on the removal efficiency and; (iv) the effect of time on the $\mathrm{Hg} 2$ removal efficiency by NOCNF at $100 \mathrm{ppm} \mathrm{Hg} 2+$ concentration at $\mathrm{pH}=7$.

\section{Supplementary Files}

This is a list of supplementary files associated with this preprint. Click to download.

- MercurysupplementaryInformationHuiChen.docx 